OPEN ACCESS

Edited by:

Sandra Maria Blois,

University Medical Center Hamburg-

Eppendorf, Germany

Reviewed by:

Sanjay Basak,

National Institute of Nutrition (ICMR),

Gabrielle Rizzuto,

University of California, San Francisco,

United States

*Correspondence:

Damián Oscar Muzzio

Damian.Muzzio@med.uni-

greifswald.de

${ }^{\dagger}$ These authors have contributed equally to this work and share last authorship

Specialty section:

This article was submitted to Immunological Tolerance and Regulation,

a section of the journal

Frontiers in Immunology

Received: 20 April 2021 Accepted: 13 August 2021 Published: 31 August 2021

Citation: Heusler M, Einenkel R, Ehrhardt J, Muzzio DO and Zygmunt M (2021)

Low Abundance Fusobacterium

Nucleatum Supports Early Pregnancy Development - An In Vitro Study.

Front. Immunol. 12:698045. doi: 10.3389/fimmu.2021.698045

\section{Low Abundance Fusobacterium Nucleatum Supports Early Pregnancy Development - An In Vitro Study}

\author{
Martha Heusler, Rebekka Einenkel, Jens Ehrhardt, Damián Oscar Muzzio *t \\ and Marek Zygmunt ${ }^{\dagger}$
}

Department of Obstetrics and Gynecology, University of Greifswald, Greifswald, Germany

Pregnancy success depends greatly on a balanced immune homeostasis. The detection of bacterial components in the upper reproductive tract in non-pregnant and pregnant women raised questions on its possible beneficial role in reproductive health. The local conditions that allow the presence of bacteria to harmonize with the establishment of pregnancy are still unknown. Among the described bacterial species in endometrial and placental samples, Fusobacterium nucleatum was found. It has been observed that $F$. nucleatum can induce tumorigenesis in colon carcinoma, a process that shares several features with embryo implantation. We propose that low concentrations of $F$. nucleatum may improve trophoblast function without exerting destructive responses. Inactivated $F$. nucleatum and $E$. coli were incubated with the trophoblastic cell lines HTR8/SVneo, BeWo, and JEG-3. Viability, proliferation, migratory capacity, invasiveness and the secretion of chemokines, other cytokines and matrix metalloproteinases were assessed. The presence of $F$. nucleatum significantly induced HTR8/SVneo invasion, accompanied by the secretion of soluble mediators (CXCL1, IL-6 and IL-8) and metalloproteinases (MMP-2 and MMP-9). However, as concentrations of $F$. nucleatum increased, these did not improve invasiveness, hindered migration, reduced cell viability and induced alterations in the cell cycle. Part of the F. nucleatum effects on cytokine release were reverted with the addition of a TLR4 blocking antibody. Other effects correlated with the level of expression of E-cadherin on the different cell lines tested. Low amounts of $F$. nucleatum promote invasion of HTR8/SVneo cells and induce the secretion of important mediators for pregnancy establishment. Some effects were independent of LPS and correlated with the expression of E-cadherin on trophoblasts.

Keywords: microbiome, pregnancy, trophoblast, Fusobacterium nucleatum, HTR8/SVneo, BeWo, JEG-3

\section{INTRODUCTION}

It is estimated that a healthy adult hosts a number of bacteria comparable in magnitude with the number of own human cells. Commonly known, skin, gut and vagina are densely colonized body sites. The colon, the site where most bacteria reside, is estimated to contain around $3.8 \times 10^{13}$ bacteria (1). The gut microbiota has established symbiotic relationships with the host bearing 
mutualistic advantages for both, bacteria and the host. The human body, thereby, profits from pathogen defense, provision of metabolites and immunological challenges mediating enteric homeostasis. Alterations in its composition, instead, may cause several health problems (2).

The gut microbiome has its origin early in life and its development depends on several factors. The colonization and thus the composition is affected by the mode of birth (3), genetic factors, nutrition and the intake of antibiotics (4-6). In recent years, the hypothesis that the infant gut is colonized in utero has gained strength upon reports describing microbial communities in meconium from neonates delivered at full term by $\mathrm{C}$-sections (7-10). The maternal origin of the in utero colonization is still under discussion, but maternal gut, uterine and oral microflora have been proposed as source as well (11). This assessment defies the consensus that has been assumed over 100 years that the healthy womb is sterile (12).

During pregnancy, immune homeostasis is crucial for pregnancy maintenance (13). Local and systemic immune adaptations facilitate the implantation and later the accommodation of the growing fetus (14-17). These adaptations include the promotion of uterine vascular remodeling and the induction of immune tolerance (18-24). Both maternal lymphocytes and fetal derived cells including trophoblast establish a complex interaction to balance the inflammatory environment providing protection against pathogens and the necessary cytokine milieu that allows local structural modifications during placentation $(17,25,26)$.

Reports supporting the idea of the sterile womb were based on data obtained from culture-based methods. However, considering that only $1 \%$ of the bacteria are cultivable, new methodologic approaches have been applied to revisit the sterile uterine model (27). A number of studies reported the presence of bacteria in healthy uterine cavity, placenta, umbilical cord and amniotic fluid $(8,28-31)$. Despite that, low bacterial loads were reported which are hardly differentiated from contaminations especially in the placenta (32-35). Furthermore, the mere detection of bacterial genetic material does not imply the presence of living bacteria. In this concern, more research is needed to clarify the impact of bacteria or bacterial products on pregnancy. Nevertheless, it has been speculated that they may play a role in priming fetal immune system or maternal inflammatory processes at the beginning of pregnancy $(36,37)$.

F. nucleatum a non-motile, non-spore-forming, gram-negative bacteria that belongs to the genus Fusobacterium of the family Bacteroidaceae (38) was found in healthy term placenta (28). It has been described as an opportunistic bacterium of the human oral cavity and one of the most occurrent species causative of periodontitis. Moreover, F. nucleatum was found in several organs, and its presence in the colon has been linked to the promotion of carcinogenesis $(39,40)$.

Many studies have been performed to determine the mechanisms by which F. nucleatum is able to modify the tumor niche. The bacterium possesses several virulence factors that suppress immune cells, promote extracellular matrix (ECM) modifications, modify blood vessel formation and induce cell growth $(39,41-48)$. Thereby, binding of Fusobacterium Adhesin A $(\operatorname{FadA})$ to E-cadherin activates $\beta$-catenin signalling and promotes direct cancer cell proliferation. The immune suppressive capacity of F. nucleatum was demonstrated more than 30 years ago (49). The same authors identified later the Fusobacterium immunosuppressive protein (FIP) and its subunit FipA are responsible for the immunosuppressive capacity of $F$. nucleatum $(50,51)$. Recently, the protein Fap2 was shown to inhibit NK cells via TIGIT (T Cell Immunoreceptor With Ig And ITIM Domains), facilitating tumor evasion of the immune system (45). Moreover, F. nucleatum can also affect humoral response and monocyte activity (52-54).

Tumor developmental mechanisms show analogies to early pregnancy processes. These include the activation of pathways that promote cell motility. For example, the reduction of the expression of adhesion molecules as E-cadherin facilitates the loss of cell-cell interactions and the epithelial-mesenchymal transition $(55,56)$. Analogous to trophoblast invasion, tumor growth is also accompanied by modifications of the ECM (57) where matrix metalloproteinases (MMPs) play a fundamental role. It has been observed that $F$. nucleatum promotes tumorigenesis by increasing the release of MMPs. Indeed, $F$. nucleatum stimulates secretion of several MMPs from epithelial cells and macrophages $(42,43,58)$ and acquires MMP-9 activity after binding of pro-MMP-9 (41). The FadA target protein, Ecadherin, is also expressed on trophoblasts in a time and location dependent manner during placental development (59-61). Expressed prominently on cytotrophoblasts in anchoring cell columns and villous trophoblasts, its expression is inversely proportional to the cell migratory capacity, being lower in extravillous trophoblasts (EVT). It has been observed that Ecadherin expression also is reduced from first to third trimester of pregnancy. While alterations in the expression of E-cadherin are associated with aberrant placentation (60), the impact of Ecadherin in cancer progression seems to depend on the cancer entity (62).

An infection can affect pregnancy not only by its virulence characteristics, but also by shifting the above mentioned inflammatory equilibrium (63). It has been proposed that placental inflammation is predominantly caused by maternal activation of TLRs (64). As shown in clinical trials, targeting bacterial infection does not warrant prevention of pregnancy complications (65). Hence, understanding immune functions at the fetomaternal interface is highly relevant. Recent studies unveiled the presence of low bacterial abundance in locations previously thought to be sterile [including endometrium, fallopian tubes $(66-68)$ and placenta $(28,29)]$. The fact that bacteria or bacterial components may be present at the fetomaternal interface challenges our understanding of local immune homeostasis.

We speculate that the presence of small numbers of $F$. nucleatum in the fetomaternal unit may influence trophoblast invasive capacity, by promoting ECM modifications and a tolerogenic surrounding micro-environment. In this work, we evaluate the effect of non-infective low concentrations of $F$. nucleatum on trophoblast biology. 


\section{MATERIAL AND METHODS}

\section{Cell Lines and Culture}

HTR8/SVneo cells (LGC Standards, Wesel, Germany), a human first trimester extravillous trophoblast immortalized cell line, were cultured in RPMI 1640 (PAN-Biotech, Aidenbach, Germany) supplemented with 10\% FBS (PAN-Biotech, Aidenbach, Germany) and 1\% penicillin/streptomycin (PANBiotech, Aidenbach, Germany).

JEG-3 (LGC Standards, Wesel, Germany) and BeWo (LGC Standards, Wesel, Germany), both human chorioncarcinoma cell lines with similar phenotype to cytotrophoblasts, were cultured in DMEM/F12 (Thermo Fisher Scientific, Schwerte, Germany) supplemented with $10 \%$ FBS and $1 \%$ penicillin/ streptomycin. All cells were cultured at $37^{\circ} \mathrm{C}$ and $5 \% \mathrm{CO}_{2}$ under humidified conditions.

\section{Preparation of Inactivated Bacteria for Stimulation}

\section{F. nucleatum}

F. nucleatum culture was kindly provided by Elsa Baufeld (Friedrich-Loeffler-Institut, University Medicine Greifswald) after growth on BD Columbia Agar with 5\% Sheep Blood (BD, Franklin Lakes, USA) under anaerobic conditions in BD GasPak (EZ pouch system BD, Franklin Lakes, USA). As obligate anaerobes, bacteria were killed by exposure to oxygen for at least $72 \mathrm{~h}$ keeping their structure unaltered (69). Inactivated bacteria were scraped off with sterile inoculating loops and washed in phosphate buffered saline (PBS; PAN-Biotech, Aidenbach, Germany). After centrifugation for $30 \mathrm{~min}$ at $4^{\circ} \mathrm{C}$ and $12000 \times g$ supernatant was discarded and the pellet was resuspended in PBS.

For stimulation, inactivated bacteria were used in a serial 10fold dilution to cover a range of MOI (multiplicity of infection) between 10 and 1000 times lower than MOI commonly used for in vitro infections $(45,70-72)$.

\section{E. coli}

E. coli was cultured in LB medium (Lennox; Carl Roth, Karlsruhe, Germany) overnight. The suspension was centrifuged for $30 \mathrm{~min}$ at $4^{\circ} \mathrm{C}$ and $12000 \times \mathrm{g}$. The pellet was resuspended in 96\% ethanol (Carl Roth, Karlsruhe, Germany) and incubated for $5 \mathrm{~min}$ to inactivate the bacteria, keeping their structure unaltered. Afterwards the suspension was washed and resuspended in PBS. As done with F. nucleatum, only inactivated bacteria were used in the experiments.

Bacterial concentration was calculated measuring the optical density assessed by the IMPLEN Nanophotometer as performed by Tuttle and colleagues (73).

\section{Invasion Assay}

$4 \times 10^{5}$ HTR8/SVneo cells were treated with inactivated $F$. nucleatum (bacteria:cell ratio of 1:100 $=0.01,1: 10=0.1,1: 1=$ $1,10: 1=10)$ or $10 \mathrm{ng} / \mathrm{mL}$ LPS for $6 \mathrm{~h}$. Conditioned media (CM) was collected and spheroids were consequently created in 5\% methyl cellulose in U-well plates overnight. Spheroids were embedded in matrigel (10 mg/mL; Corning, New York, USA).
After polymerization at $37^{\circ} \mathrm{C}$ for $2 \mathrm{~h}$ the collated $\mathrm{CM}$ was added. The growth of cell branching structures ("Sprouting") was observed and documented at the light microscope (Zeiss, Oberkochen, Germany). The area formed by connected sprout tips was measured at $0 \mathrm{~h}, 24 \mathrm{~h}$ and $48 \mathrm{~h}$ and analyzed with ImageJ.

\section{Cell Migration}

Cell migration of HTR-8/SVneo and BeWo was assessed in a scratch assay. $2 \times 10^{5}$ trophoblast cells were cultured in a 24 -well plate. Confluent cell monolayer was scratched with a pipette tip. Medium was aspirated and cells were rinsed with warm $\left(37^{\circ} \mathrm{C}\right)$ PBS twice. Afterwards control media or stimulation media (positive control EGF (Biomol, Hamburg, Germany) $40 \mathrm{ng} /$ $\mathrm{mL}$; inactivated $F$. nucleatum/E. coli $2 \times 10^{3} ; 2 \times 10^{4} ; 2 \times 10^{5}$; $\left.2 \times 10^{6}\right)$ were added. The cell-free area was measured at $0 \mathrm{~h}$ and $12 \mathrm{~h}$ (HTR8/SVneo) or $30 \mathrm{~h}$ (BeWo) (Zeiss, software: ZEN 2012 SP2) with ImageJ software and MRI Wound Healing Tool macro.

\section{Cell Viability}

Cell viability of HTR8/SVneo, JEG-3 and BeWo was determined after stimulation with inactivated $F$. nucleatum using the CellTiter-Blue ${ }^{\circledR}$ Cell Viability Assay (Promega, Mannheim, Germany). The assay is based on the capacity of living cells to convert resazurin (a redox dye) into resorufin (a fluorescent product). $5 \times 10^{3}$ cells per well were cultured in a 96 -well plate. After 30 min incubation, $F$. nucleatum suspensions were added $\left(0 ; 500 ; 5 \times 10^{3} ; 5 \times 10^{4}\right)$. After 2,24 or $48 \mathrm{~h}$ incubation $20 \mu \mathrm{L}$ CellTiter-Blue ${ }^{\circledR}$ was added and incubated for $1 \mathrm{~h}$ at $37^{\circ} \mathrm{C}$. Fluorescence was measured with BMG FLUOstar OPTIMA Microplate Reader.

\section{In-Cell Western Assay}

E-cadherin expression was determined by In-Cell Western Assay. $2 \times 10^{4}$ cells per well were cultured in a 96-well plate and incubated for $3 \mathrm{~h}$ at $37^{\circ} \mathrm{C}$ to assure adequate attachment. Cells were fixed with $3.7 \%$ formaldehyde (Carl Roth, Karlsruhe, Germany) in PBS for 20 min at room temperature. Subsequently, cells were permeabilized by adding cold methanol (Carl Roth, Karlsruhe, Germany) and shaken on ice for $20 \mathrm{~min}$. Cells were then washed with PBS and blocked with Odyssey Blocking Buffer (LI-COR Biotechnology, Bad Homburg, Germany) for $90 \mathrm{~min}$ at room temperature. The cells were then incubated with primary antibody (E-Cadherin (24E10) Rabbit mAb, Cell Signaling Technology, Leiden, Netherlands) diluted in Odyssey Blocking Buffer at $4^{\circ} \mathrm{C}$ overnight. Cells were washed with washing buffer [PBS; 0.1\% Tween 20 (Carl Roth, Karlsruhe, Germany)] and incubated with secondary antibody (IRDye ${ }^{\circledR} 800 \mathrm{CW}$ Goat antiRabbit IgG $(\mathrm{H}+\mathrm{L})$, LI-COR Biotechnology, Bad Homburg, Germany) and DRAQ5 (Cell Signaling Technology, Leiden, Netherlands), as a normalization control for cell number, diluted in antibody buffer (Odyssey Blocking Buffer; $0.2 \%$ Tween 20) for $60 \mathrm{~min}$ at room temperature. The cells were washed with washing buffer. The plate was measured with Li-Cor Odyssey Infrared Imager and analysed with Image Studio (LI-COR Biotechnology, Bad Homburg, Germany). 


\section{Apoptosis Rate and Cell Cycle Analysis}

Apoptosis rate was determined using the FITC Annexin V Apoptosis Detection Kit II (BD Biosciences, Heidelberg, Germany) according to manufacturer's instructions. Cell cycle analysis was performed with propidium iodide (PI; Sigma-Aldrich, Schnelldorf, Germany) flow cytometric assay (74). For both experiments cells were cultured in a 48-well plate. After $30 \mathrm{~min}$ incubation, inactivated $F$. nucleatum were added $\left(0 ; 3 \times 10^{3} ; 3 \times\right.$ $\left.10^{4} ; 3 \times 10^{5}\right)$. After 2,24 or $48 \mathrm{~h}$ incubation the cells were detached and stained. Measurement was done using a BD FACSCanto Flow Cytometer. Data was analysed with FlowJo software.

For cell cycle analysis, cells were stained with $50 \mu \mathrm{g} / \mathrm{ml}$ PI in hypotonic lysis buffer [0.1\% Trinatriumcitrat-2-hydrate (Carl Roth, Karlsruhe, Germany); 0.1\% Triton-X-100 (SigmaAldrich, Schnelldorf, Germany)]. The measurement followed immediately applying a BD FACSCanto Flow Cytometer. The FlowJo cell cycle analysis tool with univariate pragmatic model by Watson (75) was used to differentiate between G0/1; S; G2/ $\mathrm{M}$ phases.

\section{Determination of Cytokine- and Matrix Metalloproteinases Secretion}

The secretion of cytokines including chemokines (IL-6, IL-8, CXCL1; IL-1 $\beta$ ) and matrix metalloproteinases (MMP-2, MMP-9) was determined by ELISA (human IL-6; CXCL8/IL-8; CXCL1/GRO- $\alpha$; IL-1 $\beta$; MMP-2; MMP-9 DuoSet ELISA, R\&D, Abingdon, United Kingdom). $1 \times 10^{5}$ cells per well were cultured in a 24 -well plate and incubated for $30 \mathrm{~min}$ at $37^{\circ} \mathrm{C}$. The cells were then treated with $0 ; 10^{3} ; 10^{4}$ or $10^{5}$ inactivated $F$. nucleatum or $10^{5}$ inactivated E. coli. Supernatants were collected after $2 \mathrm{~h}$; $4 \mathrm{~h} ; 8 \mathrm{~h} ; 24 \mathrm{~h}$ or $48 \mathrm{~h}$ and centrifuged for $10 \mathrm{~min}$ at $4^{\circ} \mathrm{C}$ and $13000 \times g$ to remove dead cells and bacteria and stored at $-80^{\circ} \mathrm{C}$. The ELISAs were performed according to manufacturer's protocol. BMG FLUOstar OPTIMA Microplate Reader was used to assess colour changes and calculate the concentrations.

\section{TLR4 Blocking}

$5 \times 10^{4} \mathrm{HTR} 8 / \mathrm{SV}$ neo cells per well were cultured in a 48 -well plate and incubated for $30 \mathrm{~min}$ at $37^{\circ} \mathrm{C}$. PAb-hTLR4 (TLR4 blocking antibody; InvivoGen,Toulouse, France) was added. After $1 \mathrm{~h}$ incubation the cells were stimulated with $5 \times 10^{4}$ inactivated F. nucleatum. Supernatants were collected after $48 \mathrm{~h}$ and stored at $-80^{\circ} \mathrm{C}$.

\section{Multiplex Assay}

$5 \times 10^{4} \mathrm{HTR} 8 / \mathrm{SV}$ neo or $10^{5} \mathrm{BeW}$ cells per well were cultured in a 48 -well plate. After $1 \mathrm{~h}$ incubation the cells were stimulated with inactivated $5 \times 10^{4} \mathrm{~F}$. nucleatum. After $48 \mathrm{~h}$, the supernatant was discarded, and the cells were lysed following the protocol provided by the analyzing kit manufacturer. Proteins (3,7 - 12,2 $\mu \mathrm{g}$ per well as assessed by BCA assay) were analyzed using the NF- $\kappa B$ Signaling 6-plex Magnetic Bead Kit (Merck-Millipore, Massachusetts, USA) and measured in a Bio-Plex 200 System (Bio-Rad Laboratories, Hercules, USA). Data was expressed as fluorescence intensity normalized to the protein amount per well $(\mathrm{IF} / \mu \mathrm{g})$.

\section{Immunofluorescence}

$8 \times 10^{3}$ cells per well were seeded in $160 \mu \mathrm{g} / \mathrm{mL}$ collagen $\mathrm{G}$ coated $\mu$-Slides (Ibidi, Munich, Germany) and incubated overnight at $37^{\circ} \mathrm{C}$ in their corresponding media. The following day, TLR4 (PAb-hTLR4 (5 $\mu \mathrm{g} / \mathrm{mL})$, VIPER ( $5 \mu \mathrm{M}$; TLR4 Inhibitor Peptide Set, Novus Biologicals, Wiesbaden Nordenstadt, Germany) and Pitstop 2 (50 $\mu \mathrm{M}$; Sigma-Aldrich, Schnelldorf, Germany) were added to the corresponding wells $1 \mathrm{~h}$ before treatment with inactivated $F$. nucleatum in a $1: 1$ proportion. After $1 \mathrm{~h}$ stimulation, culture media was discarded and cells were fixed with $4 \%$ paraformaldehyde. Immune staining was performed with Phospho-NF-kB p65 (Ser536) (clone 93H1; 1:200) Rabbit $\mathrm{mAb}$ or $\beta$-Catenin (clone L54E2; 1:200) Mouse mAb (CellSignalling Technology, Frankfurt, Germany) overnight. The staining with secondary antibodies was performed for $2 \mathrm{~h}$ at RT in the dark with Goat anti-Mouse IgG $(\mathrm{H}+\mathrm{L})$ Highly Cross-Adsorbed Secondary Antibody, Alexa Fluor 594 (ThermoFisher Scientific, Schwerte, Germany) and Goat antiRabbit IgG $(\mathrm{H}+\mathrm{L})$ Highly Cross-Adsorbed Secondary Antibody, Alexa Fluor 488 (ThermoFisher Scientific, Schwerte, Germany), both in a concentration of 1:500. Slides were stained with $1 \mu \mathrm{g} /$ $\mathrm{mL}$ Hoechst 33258 and analyzed on a Zeiss Axiom microscope at $60 \times$. The exposure time was set constant for each cell line across experiments (green channel: $840 \mathrm{~ms}$; red channel: $400 \mathrm{~ms}$; blue channel: $17 \mathrm{~ms}$ ). The quantification of fluorescence signal was performed with ZEN 2012 Blue Edition.

\section{Statistics}

Experiments were performed independently in replicates as described in the figure legends. Data were analyzed by GraphPad Prism 5 and 8. Data were assumed normally distributed. For the effect of bacterial treatment on trophoblast biology concerning invasion, migration, viability, apoptosis, cell cycle and cytokine expression Repeated Measures ANOVA with Dunnett's multiple comparison post test or Šidák's multiple comparison test was performed. Significant differences were indicated with asterisks ${ }^{\star} \mathrm{p}_{\mathrm{adj}}<0.05 ;{ }^{\star *} \mathrm{p}_{\mathrm{adj}}<0.01$; and ${ }^{* * *} \mathrm{p}_{\mathrm{adj}}<0.001$.

\section{RESULTS}

\section{High Concentrations of Inactivated $F$. nucleatum Reduce Trophoblast Viability}

During the remodelling of spiral arteries, trophoblast invasion is associated with a constant turnover including cycles of apoptosis and cell growth (76). We assessed cell viability in trophoblasts treated with $F$. nucleatum (Figure 1A). No effect on HTR8/ SVneo viability was observed at $2 \mathrm{~h}$. Compared to unstimulated control, the viability of HTR8/SVneo cells was significantly reduced after 24 and $48 \mathrm{~h}$ after stimulation with $F$. nucleatum concentrations of 1 bacterium per cell and 10 bacteria per cell.

Similar to HTR8/SVneo, JEG-3 viability was significantly reduced after $24 \mathrm{~h}$ and $48 \mathrm{~h}$ but only by a concentration of 10 bacteria per cell at $24 \mathrm{~h}$ and $48 \mathrm{~h}$. In contrast to HTR8/SVneo and 

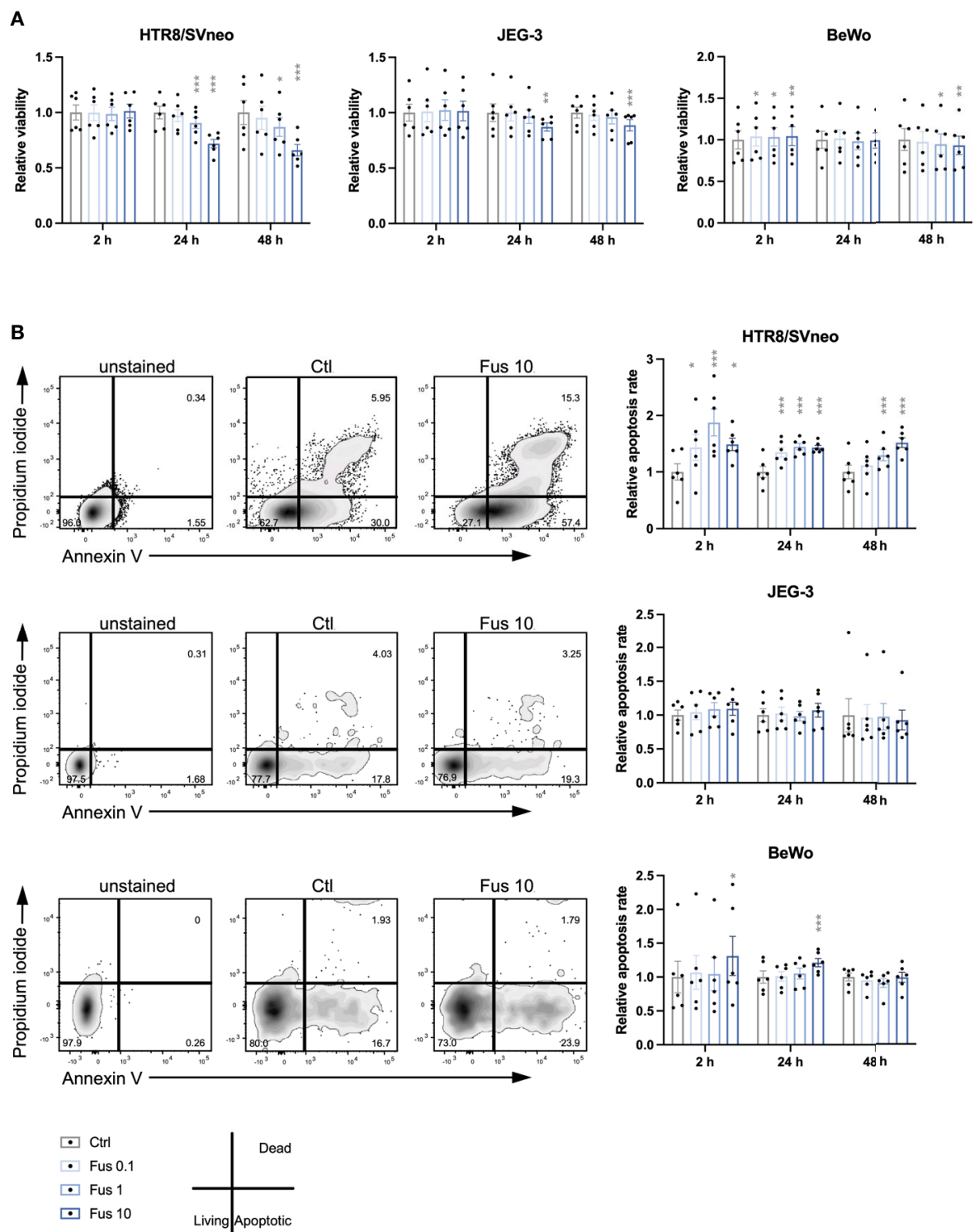

FIGURE 1 | Reduced viability and increased apoptosis rate of HTR8/SVneo cells was seen in response to high concentrations of inactivated $F$. nucleatum. Bar graphs represent viability of trophoblast cell lines after stimulation with $F$. nucleatum normalized to respective controls (A). Representative plots for the analysis of apoptosis rate of HTR8/SVneo, JEG-3 and BeWo cells by flow cytometry (B left). Bar graphs show apoptosis rate of trophoblast cell lines after stimulation with $F$. nucleatum normalized to respective controls (B right). Normalized data represent the quotient of each value to the mean of untreated controls. Data are presented as mean \pm SEM. ${ }^{*} p_{a d j}<0.05 ;{ }^{* *} p_{a d j}<0.01 ;{ }^{* \star} p_{a d j}<0.001$ as analysed by Repeated Measures ANOVA with Dunnett's multiple comparison post test, comparing each treatment against the corresponding control. Experiments were performed 6 times in sixtuplicate (A) or in triplicates (B). Each point represents the mean value of the replicates for each experiment. Ctl, control; Fus, ratio of $F$. nucleatum to cell number.

JEG-3, BeWo cells showed a different pattern in their viability after treatment with $F$. nucleatum. While all $F$. nucleatum concentrations increased viability after $2 \mathrm{~h}$, concentrations of 1 and 10 bacteria per cell had a negative effect on viability after $48 \mathrm{~h}$.

Overall, we observed that the viability of the cell lines varied in response to treatment with inactivated $F$. nucleatum. High concentrations of inactivated $F$. nucleatum decreased viability of HTR8/SVneo and BeWo cells after 24 and $48 \mathrm{~h}$ treatment.
In contrast, a short stimulation with bacteria $(2 \mathrm{~h})$ enhanced cell viability in BeWo cells.

\section{Higher F. nucleatum Concentrations Increase Apoptosis Rate in HTR8/SVneo and BeWo}

Considering the effects of F. nucleatum treatment on trophoblast viability, the apoptosis rate was consequently assessed (Figure 1B). In HTR8/SVneo, a significant increase of the 
frequency of apoptotic cells by all F. nucleatum concentrations was visible after $2 \mathrm{~h}$ and $24 \mathrm{~h}$. After $48 \mathrm{~h}$, the apoptosis rate was increased by $F$. nucleatum concentrations of 1 bacterium per cell and 10 bacteria per cell but not by concentrations of 0.1 bacterium per cell.

In contrast to HTR8/SVneo, the apoptotic rate of both choriocarcinoma cell lines was less affected by inactivated $F$. nucleatum. While apoptosis in JEG-3 cells was not influenced by the treatment, BeWo cells increased apoptosis rate by $F$. nucleatum concentrations of 10 bacteria per cell at $2 \mathrm{~h}$ and $24 \mathrm{~h}$.

In terms of induction of apoptosis, HTR8/SVneo cells showed an increased susceptibility to F. nucleatum compared to BeWo and especially JEG-3 cells.

\section{Lower Concentration of $\boldsymbol{F}$. nucleatum Supports Trophoblast Invasion}

To test our hypothesis that low concentrations of F. nucleatum may improve trophoblast invasiveness, an invasion assay using trophoblast spheroids embedded in matrigel was performed (Figures 2A, B). After treatment with F. nucleatum, the sprouting area formed by connecting sprout tips was assessed after $48 \mathrm{~h}$ and normalized to the initial spheroid area at $0 \mathrm{~h}$.

HTR8/SVneo cells tended to increase invasion depth (area formed by the connection of the outer sprout tips) with rising bacterial concentration. Compared to the control, this increase was significant for 0.1 , up to 1 bacteria per cell but decreased to control level with higher bacterial concentration (10 bacteria per cell).

\section{Lower Bacterial Amounts Do Not Affect Trophoblast Migration}

Invasion is a complex mechanism of matrix degeneration and cellular motility. In order to determine the mechanisms by which F. nucleatum promoted trophoblast invasiveness, we studied effects of bacteria treatment on cell migration. In contrast to the effects observed in invasiveness, no significant effects were observed for the treatment with low concentrations of bacteria up to a ratio of one bacterium per cell. However, treatment with F. nucleatum at a ratio of 10 bacteria per cell lead to a significant decrease in the migratory capacity of HTR8/SVneo (Figures 2C, D).

E. coli treatment did not significantly influence migration of HTR8/SVneo. On BeWo cells, neither E. coli (data not shown) nor F. nucleatum stimulation had any significant effect on cell migration (Figure 2C).

As the re-growth of the scratched area depends not only on cell viability but also proliferation, we moved forward to assess this in trophoblasts treated with F. nucleatum.

\section{F. nucleatum Induces Growth Arrest in JEG-3 and BeWo but Turnover in HTR8/SVneo}

To test the biological effect of $F$. nucleatum on trophoblast proliferation behaviour, we investigated the cell cycle phases with DNA staining and flow cytometry (Figure 3).

In the HTR8/SVneo cell line, F. nucleatum induced an increment of the proportion of cells in the $\mathrm{G} 2 / \mathrm{M}$ phase at ratios 1 and 10 bacteria per cell. After $24 \mathrm{~h}$, this was accompanied by a decrease of cells in $S$ phase. The effects of 0.1 bacteria per cell were observed only after $48 \mathrm{~h}$. Here, an increment of the of the G0/G1 phase and a decrease of S phase was induced after treatment.

In contrast to HTR8/SVneo cells, JEG-3 cells reacted to the treatment with $F$. nucleatum by through a reduction of the G2/M phase after $2 \mathrm{~h}$ (at ratios 1 and 10) and $24 \mathrm{~h}$ (all concentrations). These changes were accompanied by an increment of the G0/G1 phase and, after $24 \mathrm{~h}$, a reduction of the S phase. After $48 \mathrm{~h}$, only significant changes in the G0/G1 phase (an increment) could be observed at ratios 1 and 10 .

Similar to JEG-3 cells, F. nucleatum treatment led to a reduction of the G2/M phase (after $2 \mathrm{~h}$ at ratios 1 and 10 , after $24 \mathrm{~h}$ at a ratio of 0.1 ) and an accumulation of cells in the G0/G1 phase (after $2 \mathrm{~h}$ at ratios 1 and 10, after $24 \mathrm{~h}$ for all ratios) in BeWo cells. Ratios of 10 bacteria per cell also reduced the $\mathrm{S}$ phase after $24 \mathrm{~h}$ and $48 \mathrm{~h}$.

Overall, we observed that F. nucleatum treatment led to an increased proportion of cells in G2/M of HTR8/SVneo, but to an accumulation of cells in G0/G1 of JEG-3 and BeWo.

\section{F. nucleatum Treatment Induces Secretion of Pro-Invasive Mediators in HTR8/SVneo but Not in BeWo}

Certain pro-inflammatory cytokines, acting paracrinally or autocrinally, promote invasion of trophoblasts. Furthermore, trophoblasts secrete matrix metalloproteinases (MMPs) facilitating the invasion of trophoblasts. We analyzed the effect of F. nucleatum treatment on the secretion of pro-inflammatory cytokines and MMPs in trophoblasts cell lines.

CXCL1, IL-8 and MMP-9 were only detectable in the supernatants of HTR8/SVneo, but not in BeWo nor JEG-3 supernatants (Figure 4A). The chemokine CXCL1 was induced after $24 \mathrm{~h}$ and $48 \mathrm{~h}$ of treatment with $F$. nucleatum at a ratio of 1 bacterium per HTR8/SVneo cell. Similarly, after $24 \mathrm{~h}$ an induction of IL- 8 and MMP-9 secretion could be detected at a ratio of 1 bacterium per HTR8/SVneo cell. In contrast, E. coli stimulation induced the secretion of CXCL1, IL-8 and MMP-9 in al time points analyzed.

IL- 6 and MMP-2 were detectable in the supernatants of both HTR8/SVneo and BeWo (Figure 4B).

The secretion of IL- 6 by HTR8/SVneo was increased by F. nucleatum as well as E. coli stimulation in all time points. In contrast, the treatment of BeWo cells with F. nucleatum led to a decreased IL-6 secretion, while no effect of $E$. coli treatment could be observed. Similarly, F. nucleatum stimulation induced MMP2 secretion from HTR8/SVneo, but decreased it in BeWo cells. No significant effect was observed after treatment with $E$. coli in both cell lines.

IL-1 $\beta$ concentration was below the detection threshold of 250 $\mathrm{pg} / \mathrm{mL}$ in all trophoblast cell supernatants.

Similar to the previous results, HTR8/SVneo showed a stronger reaction as compared to BeWo. High bacterial concentrations led to a stronger secretory response in HTR8/ SVneo (CXCL1, IL-6, IL-8, MMP-2 \& -9). However, in BeWo 
A

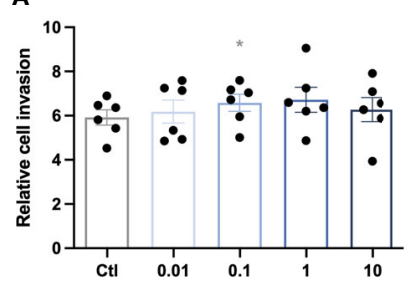

C

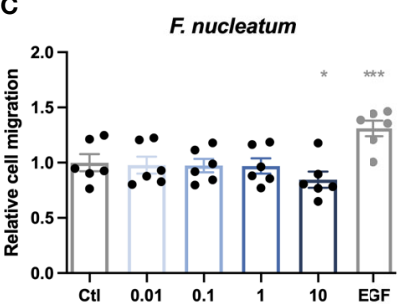

E. coli

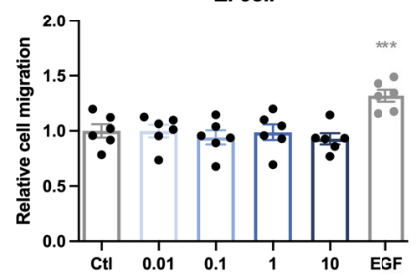

E

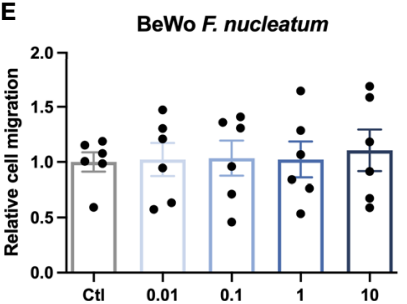

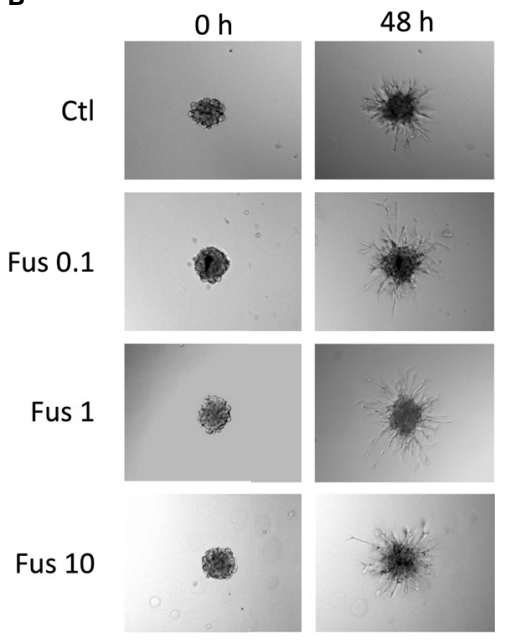

D

$\mathrm{Oh}$
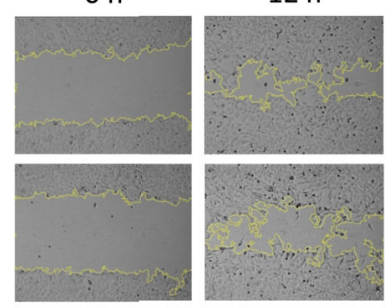

E. coli 10
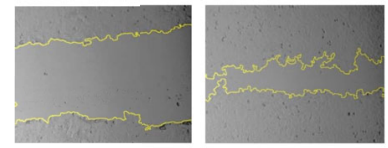

EGF

FIGURE 2 | Low concentrations of inactivated F. nucleatum promote HTR8/SVneo invasion; high concentration of inactivated $F$. nucleatum impairs migration of HTR8/SVneo cells. HTR8/SVneo cells were stimulated with F. nucleatum for $6 \mathrm{~h}$ using indicated bacteria:trophoblast ratios. After culture in methyl cellulosecontaining medium, spheroids were embedded in matrigel and observed to analyse invasive behaviour (A, B). Bar graph shows relative sprouting expansion after 48 h normalized to spheroid size at 0 h (A). Data are presented as mean \pm SEM and were analysed by Repeated Measures ANOVA with Dunnett's multiple comparison post test, comparing each treatment against the corresponding control. ${ }^{*} p_{a d j}<0.05$ Representative microscopic images are shown (B). Experiments were performed 6 times. Scratch assay was performed to assess the migratory behaviour of bacteria-treated trophoblasts (C-E). EGF was used as positive control. Inactivated bacteria were added in different ratios $(0.01 ; 0.1 ; 1 ; 10$ bacteria per trophoblast cell). Bar graphs represent relative area recovered by HTR8/Svneo treated with either F. nucleatum (above) or E. coli (below) after $12 \mathrm{~h} \mathrm{(C)} \mathrm{or} \mathrm{BeWo} \mathrm{treated} \mathrm{with} \mathrm{F.} \mathrm{nucleatum} \mathrm{after} 30$ h (E) normalized to unstimulated control. Data are presented as mean \pm SEM. ${ }^{\star} p_{a d j}<0.05 ;{ }^{\star \star \star} p_{a d j}<0.001$ as analysed by Repeated Measures ANOVA with Dunnett's multiple comparison post test, comparing each treatment against the corresponding control. Experiment was performed 6 times in quadruplicate (C) or triplicate (E). Each point represents the mean value of the replicates for each experiment. Representative microphotographs of HTR8/SVneo taken with a $10 \times$ objective taken after 0 and $12 \mathrm{~h}$ of the scratch (D). EGF, epidermal growth factor; Ctl, control.

cells responded with a decreased release of the investigated factors (IL-6, MMP-2) even with the low bacterial concentration.

\section{NF-אB Mediates TLR4 Dependent $F$. nucleatum Actions on HTR8/SVneo Cells}

The differences in the response to bacteria between HTR8/SVneo and both, JEG-3 and BeWo cell lines, suggested that there may be differences in the ability to sense F. nucleatum.
Since the interaction between F. nucleatum protein FadA and epithelial cells results from the interaction with E-cadherin (44), the basal expression of E-cadherin on the cell lines was assessed (Figures 5A, B). The relative E-cadherin signal (normalized as a ratio to HTR8/SVneo signal) was $\sim 10$ times higher in BeWo and JEG-3 than in HTR8/SVneo.

Besides the interaction with E-cadherin, gram-negative bacteria can be sensed by their LPS via TRL4 signalling and cause a pro- 
A

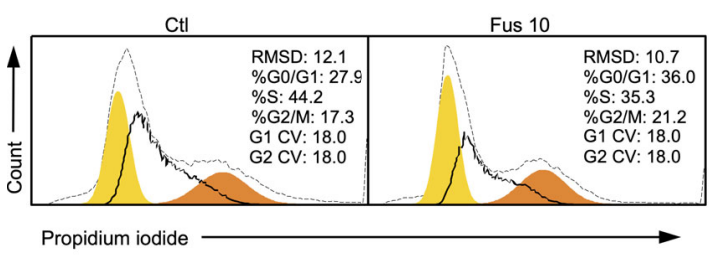

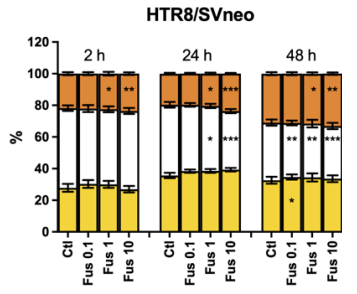
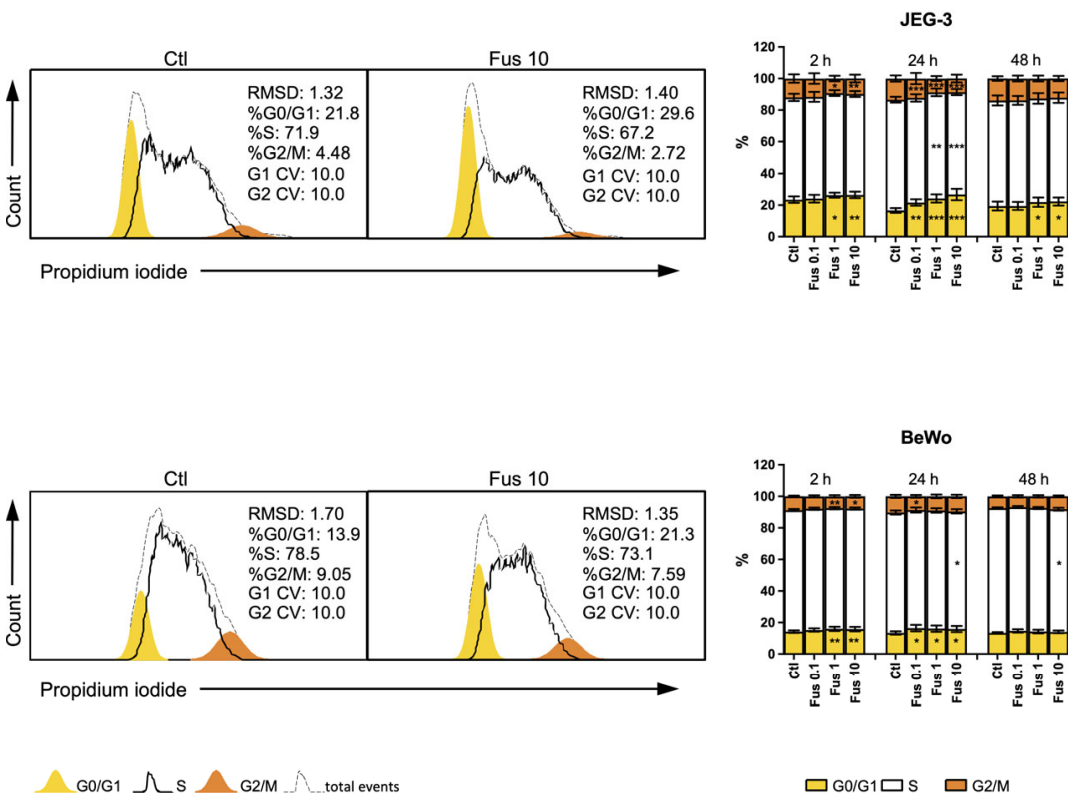

FIGURE 3 | Inactivated F. nucleatum increases the frequency of HTR8/SVneo cells in G2/M phase and JEG-3 and BeWo G0/1 phase. HTR8/Svneo, JEG-3 and BeWo were stimulated with different concentrations of $F$. nucleatum. Cell cycle analysis was performed after 2, 24 or $48 \mathrm{~h}$. Representative cell cycle analysis of unstimulated control and Fus10 (A). Bar graphs show percentages of cells in the different cell cycle phases (B). Data are presented as mean \pm SEM. ${ }^{*} p_{a d j}<0.05$; ${ }^{* \star} \mathrm{P}_{\mathrm{adj}}<0.01 ;{ }^{* \star *} \mathrm{p}_{\mathrm{adj}}<0.001$ as analysed by Repeated Measures ANOVA with Dunnett's multiple comparison post test, comparing each treatment against the corresponding control. Experiments were performed 6 times in triplicate. Each point represents the mean value of the replicates for each experiment. RMDS, Root Mean Square Deviation; G0/G1 and G2/M main peak modeled as a Gaussian distribution, S calculated; CV, Coefficients of Variation; Ctl, control; Fus, ratio of $F$. nucleatum to cell number.

inflammatory reaction as observed in HTR8/SVneo. Interestingly, it has been observed that BeWo respond less sensitively to LPS stimulation than other trophoblast cells lines as JEG-3 and do not follow classical NF- $\kappa B$ pathway activation (77). In order to determine the impact of TLR4-dependent signalling, we performed the experiments in the presence and absence of a TLR4-blocking antibody (Figure 5C). The presence of the antibody led to a significant dose-dependent reduction of F. nucleatum-induced IL-6 secretion in HTR8/SVneo. Furthermore, F. nucleatum induced the activation of the NF- $\kappa \mathrm{B}$ pathway, leading to increased phosphorylation of the The IKB kinase $\alpha$ (IKK $\alpha$ ) in HTR8/SVneo while no activation of IKK $\alpha$ was detected in BeWo cells (Figure 5D).

To gain further insights into the signaling pathways triggered by F. nucleatum following TLR4 and E-cadherin activation, NF$\kappa \mathrm{B}$ and $\beta$-catenin were analyzed microscopically in the presence of inactivated F. nucleatum and inhibitors of TLR4 and E- cadherin pathways. Untreated HTR8/SVneo and BeWo cells showed cytoplasmic expression of NF- $\kappa \mathrm{B}$. After $1 \mathrm{~h}$ treatment, $\mathrm{NF}-\kappa \mathrm{B}$ was detected predominately close to and within the nucleus of HTR8/SVneo cells (Figure 6, top). The addition of TLR4-blocking antibody or the inhibitor TLR4-VIPER prior to bacterial treatment reverted this activation.

The transcription factor $\beta$-catenin mediates E-cadherin signals triggered by the binding of the F. nucleatum FadA adhesin molecule. BeWo cells displayed higher levels of $\beta$-catenin expression than HTR8/SVneo cells. Nuclear localization of $\beta$ catenin was found in a low number of cells BeWo, slightly more frequently after treatment with $F$. nucleatum. The use of the $\beta$ catenin inhibitor Pitstop 2 led to a slightly less, but not significant reduction of $\beta$-catenin signal after $F$. nucleatum treatment.

This data confirms that $F$. nucleatum triggers TLR4/NF- $\kappa B$ pathway activation and suggests that $\mathrm{E}$-cadherin/ $\beta$-catenin 

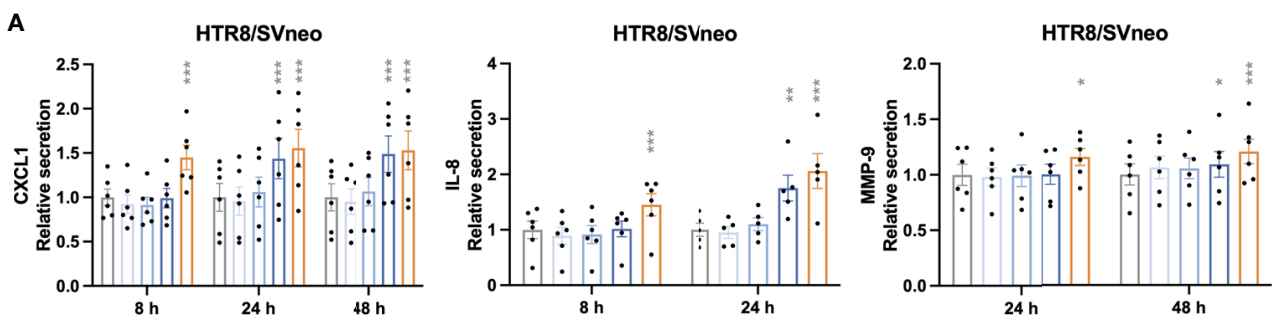

B

HTR8/SVneo
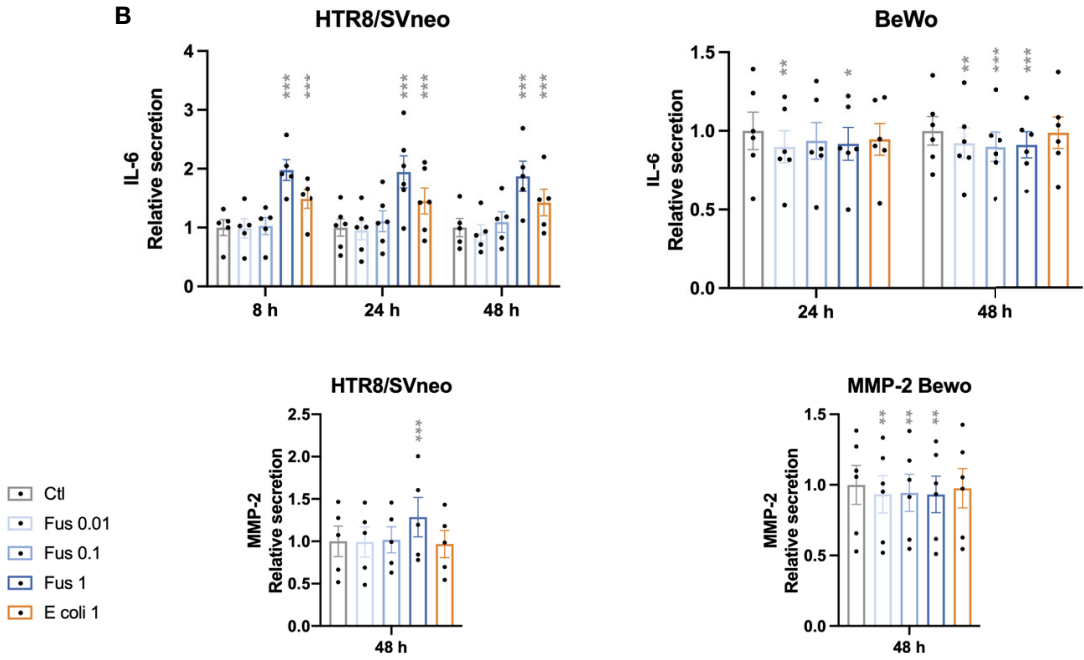

FIGURE 4 | Inactivated F. nucleatum and E. coli augment secretion of pro-inflammatory cytokines and MMPs by HTR8/SVneo cells. Bar graphs represent secretion of cytokines and matrix metalloproteinases (MMP) by trophoblast cell lines after stimulation with $F$. nucleatum normalized to respective unstimulated controls (A, B). Data are presented as mean \pm SEM. ${ }^{*} p_{a d j}<0.05 ;{ }^{* *} p_{a d j}<0.01 ;{ }^{* * *} p_{a d j}<0.001$ as analysed by Repeated Measures ANOVA with Dunnett's multiple comparison post test, comparing each treatment against the corresponding control. Experiments were performed 5 (IL-8, MMP-2 and IL-6 in HTR8/SVneo) or 6 (CXCL1, MMP-9 and IL-6 in BeWo) times in duplicate. Each point represents the mean value of the replicates for each experiment. Ctl: control; Fus: ratio of $F$. nucleatum to cell number (if no number given ratio is 1 ); $\mathrm{E}$. coli 1 : ratio of E. coli to cell number $=1$.

pathway is likely more predominant in BeWo than in HTR8/ SVneo cells.

\section{DISCUSSION}

Although several studies support the idea that bacterial communities are present in the upper reproductive tract, their physiological impact remains still speculative. In this work, we have tested the hypothesis that the presence of low amounts of $F$. nucleatum can modulate trophoblast function without eliciting a major destructive inflammatory response.

It has been postulated that bacteria may exert a modulatory effect on trophoblast function through interactions between bacterial LPS and TLR4 expressed on the cell surface $(36,78)$. Both E. coli and F. nucleatum are gram-negative bacteria, thus they can induce LPS-mediated responses. Indeed, several studies addressed LPS-mediated effects of $F$. nucleatum in tumorigenesis and placental pathology (79-83). It is likely that the induction of pro-inflammatory responses we observed were LPS-mediated as well. However, certain responses differed between the treatments with F. nucleatum and E. coli (release of cytokines including chemokines).

As comparable amounts of bacteria have been used, discrepancies between both responses may be caused by other bacterial components than LPS. F. nucleatum has several virulence factors and is known to possess immunomodulatory properties, including a number of cell-surface components called adhesins $(45,49-51,84)$. The adhesin FadA, for example, binds $\mathrm{E}$-cadherin and activates NF- $\mathrm{\kappa B}$ downstream (44). In the context of colorectal cancer, $F$. nucleatum is associated with the promotion of tumorigenesis and the modulation of the tumoral immune environment $(44,85,86)$. At the same time, F. nucleatum has the ability to induce modifications of the extracellular matrix and promote tumor invasion (39, 41, 42, 58). In the fetomaternal interface, these processes are part of physiological adaptations that permit trophoblast invasion of uterine spiral arteries. Trophoblasts undergo phenotypical changes during placentation and in the course of pregnancy. This includes adaptations in changes of the expression of TLR4 and E-cadherin influencing presumably interactions with LPS and FadA, on the surface of F. nucleatum. 
A

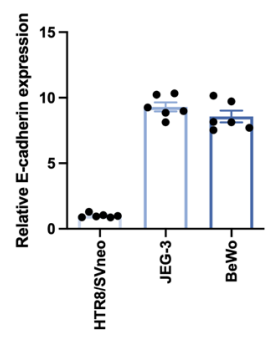

C

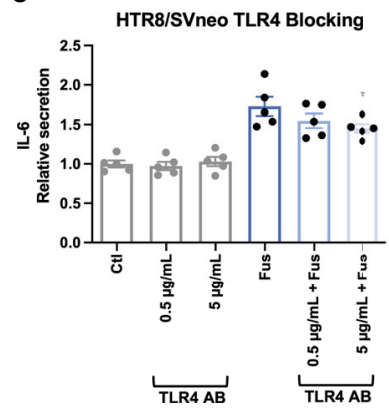

B

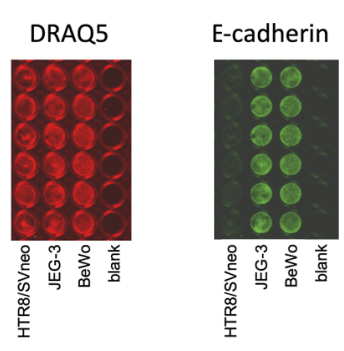

D

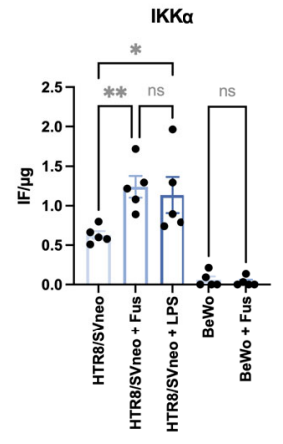

FIGURE 5 | BeWo and JEG-3 cells, but not HTR8/SVneo cells express high levels of E-cadherin. IL-6 secretion in response to bacterial stimulation of HTR8/ SVneo is partially TLR4 dependent. Bar graphs show E-cadherin expression in trophoblast cell lines normalized to HTR8/SVneo (A). E-cadherin expression was normalized to cell number detected by cell nuclei staining with DRAQ5. Illustrative image of fluorescence signals of DRAQ5 binding and E-cadherin In-Cell Western analysis (B). IL-6 secretion was assessed in HTR8/SVneo after stimulation with F. nucleatum in the presence or absence of a TLR4-blocking antibody (C). The presence of the activated form of IKK $\alpha$ on HTR8/SVneo and BeWo cells was assessed after stimulation with F. nucleatum or LPS (D). Data are presented as mean \pm SEM. The experiment was performed once in sextuplicate (A), six times in triplicate (C) or five times in duplicate (D). ${ }^{*} p_{\text {adj }}<0.05$; ${ }^{* *} p_{a d j}<0.01$; ns, not significant, as analysed by Repeated Measures ANOVA with Dunnett's (C) or Šidák's (D) multiple comparison post test. Data comparison in (C) was performed on F. nucleatum treated cells employing the group without TLR4blocking antibody as control ("Fus" column).

In our experiments, trophoblast cell lines responded differently to the same bacterial stimulation. In terms of antigen recognition, BeWo responds poorly to LPS stimulation and lacks LPS-mediated activation of the NF- $\kappa B$ pathway (77). We observed that HTR8/SVneo responded to F. nucleatum stimulation in a more sensitive way than BeWo and JEG-3. In contrast to BeWo and JEG-3, HTR8/SVneo E-cadherin expression levels were lower. This supports the idea that $F$. nucleatum shapes the responses of JEG-3 and BeWo by FadAE-cadherin interaction. JEG-3 cells, which express both functional TLR4 and high E-cadherin levels, showed a mild or an intermediate reaction to bacterial stimulation. Cytokines in the supernatant of bacteria-treated JEG-3 were under the limit of detection.

The use of trophoblast cell lines with different TLR4 function and E-cadherin expression allowed us to evaluate two scenarios, one in which TLR4-LPS interaction would predominate over

E-cadherin-FadA interactions (HTR8/SVneo), and a second one where E-cadherin is highly express and TLR4 is less functional (BeWo) (77). We speculate that the differences observed in the interaction between F. nucleatum and HTR8/SVneo, JEG-3 and BeWo cells depend on the balance between the relative expression of E-cadherin and the induction of TLR4-mediated signals. A deeper analysis of the activation of the signalling pathway depicted that, similar to LPS, F. nucleatum induced activation of the I $\kappa$ B kinase $\alpha$ (IKK- $\alpha$ ), a downstream mediator of TLR4 activation pathway. Concomitantly, the treatment led to a nuclear translocation of NF- $\kappa \mathrm{B}$. Furthermore, the use of a neutralizing antibody against TLR4 resulted in reduce cytokine production after treatment with $F$. nucleatum.

In the BeWo cell line, no activation of the TLR4 pathway could be detected by multiplex analysis. However, nuclear translocation of NF- $\kappa \mathrm{B}$ could be observed microscopically after $1 \mathrm{~h}$ treatment. In BeWo, the elevated expression of E-cadherin and $\beta$-catenin suggests a higher involvement of the E-cadherin/ $\beta$-catenin complex in the $F$. nucleatum-mediated effects on BeWo cells than in HTR8/SVneo cells. Further research is needed to determine precisely the molecular components involved in the interaction between F. nucleatum on BeWo.

Besides cell-line specific responses, we observed that presumably LPS-mediated actions (those observed in HTR8/ SVneo and that were similar to the stimulation with E. coli) were only significant after reaching relatively high concentrations of bacteria. On the other hand, LPS-independent effects, as we observed in BeWo cells, were also evident with low concentrations of fusobacteria. F. nucleatum is a bacterium with proven placental tropism (87-90) and F. nucleatum infections have been associated with intra-amniotic infection and the induction of preterm birth (91-93). The involvement of $F$. nucleatum in early pregnancy disorders needs to be further investigated. First trimester infections are associated to placenta development problems (94-97). In the context of malaria, Plasmodium-infection affects the placental vascular development, as seen by a reduced transport capacity, syncytiotrophoblast knotting, thickening of the basal membrane, decreased trophoblast invasion and inflammatory disorders (disruption of the cytokine milieu and immune cell recruiting) (98). Our data suggests that uncontrolled infections with F. nucleatum in early pregnancy might impact placental development as well.

However, the presence of bacteria does not necessarily indicate an infection. It has been observed that trophoblasts can modulate the response of immune cells to LPS, leading to contradictory effects between low and high dose stimulations (99). This has been discussed as a possible mechanism to prevent excessive pro-inflammatory reactions leading to fetal damage. The benefit of weak LPS stimulation to restore fertility has been observed in animal models. Cows with purulent vaginal discharge treated with a low dose of LPS showed improved pregnancy rate as compared to treatment with high LPS concentrations $(100,101)$. Although, eutherian mammal placentation varies in their invasive and opposing nature between fetus and maternal tissue (humans: hemochorial, ruminants: synepitheliochorial), it is driven by mild 

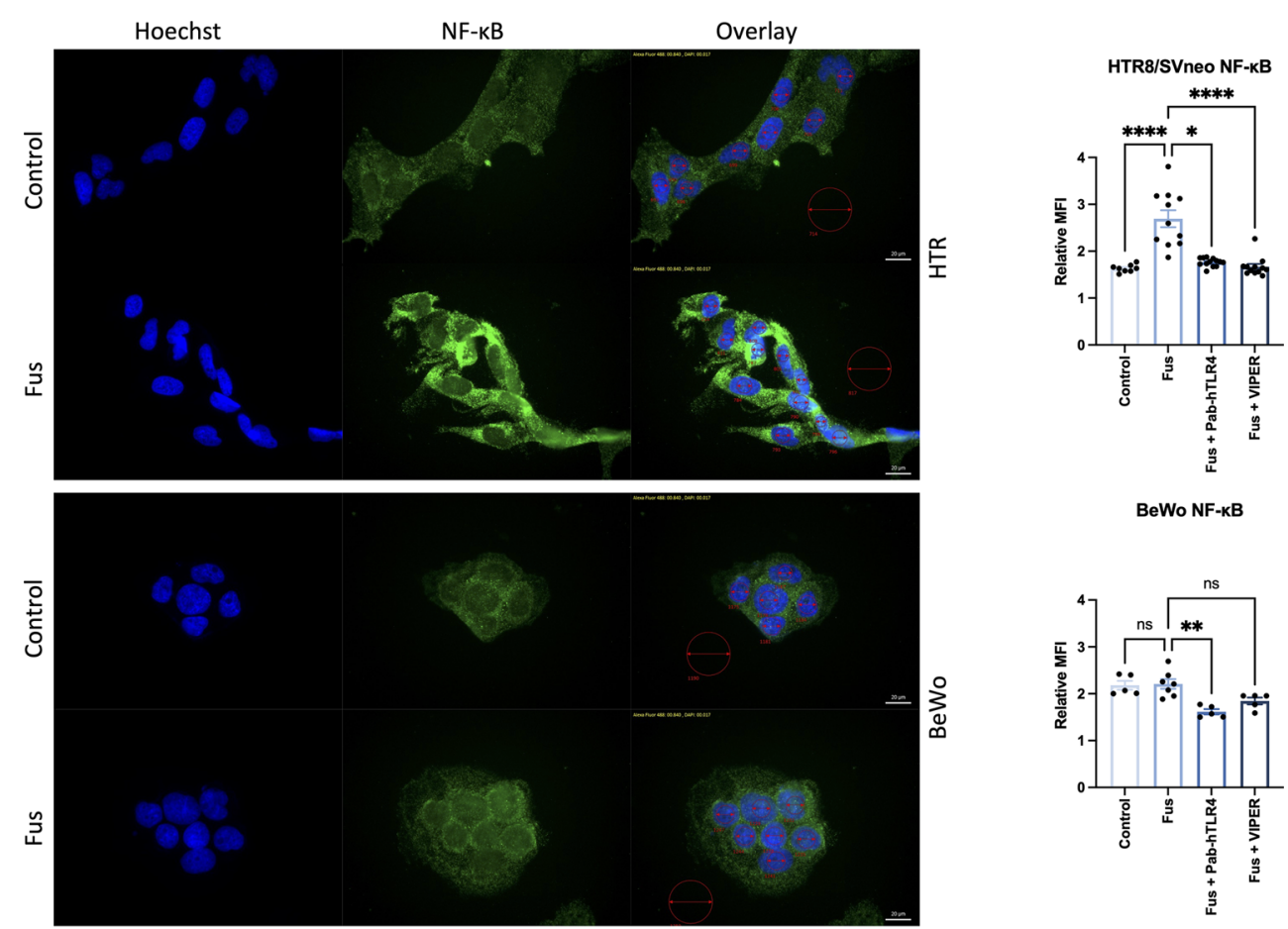

BeWo NF-KB
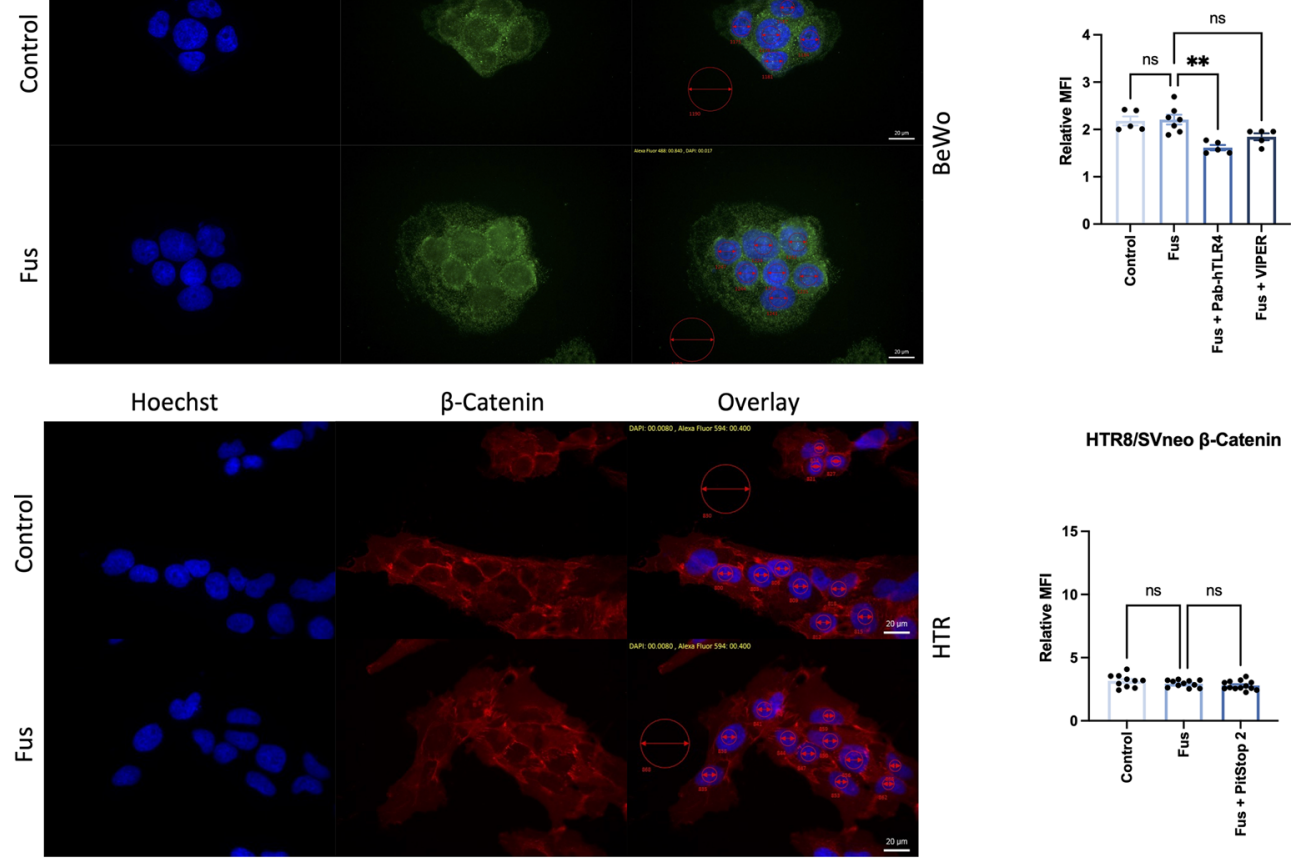

\section{HTR8/SVneo $\beta$-Catenin}
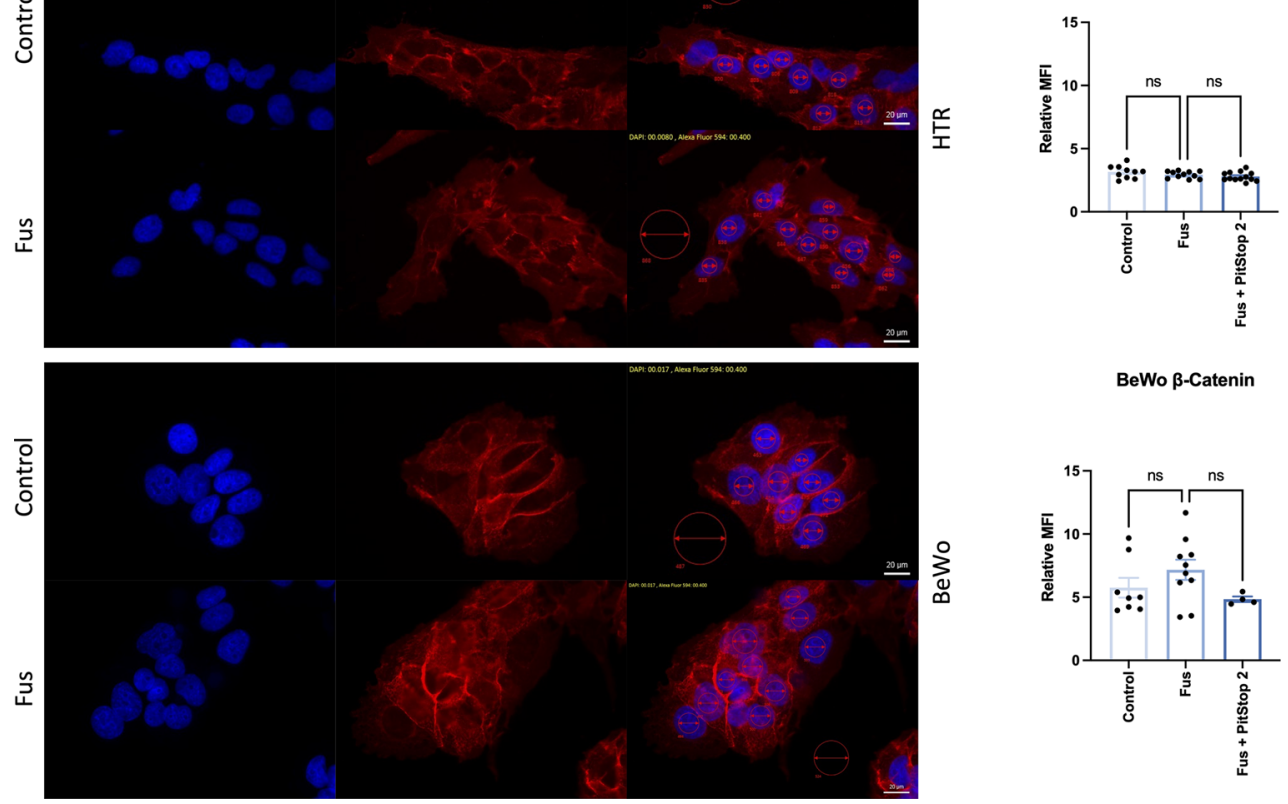

BeWo $\beta$-Catenin

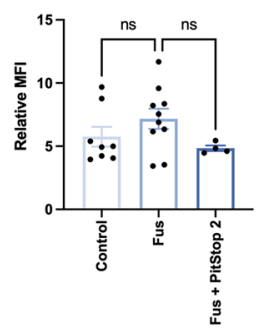

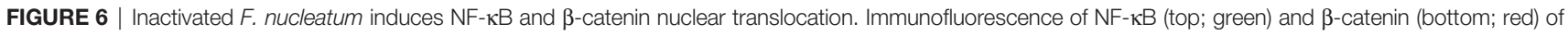
untreated or inactivated $F$. nucleatum-treated $(1 \mathrm{~h}, \mathrm{MOI}=1) \mathrm{HTR} 8 / \mathrm{SV}$ neo and BeWo cells. Some wells were previously treated with a neutralizing antibody against TLR4 (PAb-hTLR4 ( $5 \mu \mathrm{g} / \mathrm{mL})$, the viral inhibitory peptide of TLR4 (VIPER; $5 \mu \mathrm{M}$ ) or Pitstop 2 (known to interfere with E-cadherin/ $\beta$-catenin signaling) $1 \mathrm{~h}$ before bacteria treatment. Nuclei were stained with Hoechst 33258 (blue). Pictures were taken at 60x and the mean fluorescence intensity (MFI) of each channel were quantified in the nuclei (small red circles). All pictures were taken using the same exposure time (green channel: $840 \mathrm{~ms}$; red channel: $400 \mathrm{~ms}$; blue channel: $17 \mathrm{~ms}$ ). Data (left) depict the MFI (mean \pm SEM) of either NF-kB or $\beta$-catenin normalized to background (big red circle) for each picture shown. Data comparison was performed by ANOVA Kruskall-Wallis test with Dunns multiple comparison test using F. nucleatum treated cells as control ("Fus" column). "$p_{a d j}<0.05 ;{ }^{\star *} p_{a d j}<0.01$; ${ }^{\star \star \star \star} p_{\text {adj }}<0.0001 ;$ ns, not significant. 
immunological activation, which is limited as exuberant activation would cause rejection. The studies describing mechanisms suppressing excessive pro-inflammatory responses at the fetomaternal interface suggest that the presence of bacteria in low concentrations or bacterial products can be well tolerated. Furthermore, it has been speculated that a weak, non-destructive activation of immune cells may actually be favorable in early pregnancy events as well $(36,37)$.

In order to evaluate possible mechanisms in which low, noninfective concentrations of bacteria may promote early pregnancy events, we studied the F. nucleatum-trophoblast interactions in vitro. In our experimental setup, we evaluated the role of increasing concentrations of $F$. nucleatum in a range which lies between 10 and 1000 times lower than MOIs used in infection based in vitro experiments. Using this range, we aimed to detect the concentrations where the positive effects of $F$. nucleatum on trophoblast function overcome destructive excessive inflammatory responses. The analysis of the invasiveness of HTR8/SVneo depicts this concept perfectly, where a maximum effect can be observed around Fus0.1-1, while lower or higher concentrations seem to be less effective. Unfortunately, due to the fast migratory kinetics of HTR8/SVneo cells, it was not possible to perform the scratch assay at the same time point as the invasion assay. $12 \mathrm{~h}$ might be a precipitated time point to evidence positive effects of lower F. nucleatum concentrations on cell migration.

It can be speculated that the lower the concentration of $F$. nucleatum is, the weaker its effect on the release of soluble mediators that promote trophoblast invasiveness shall be (see schematic overview, Figure 7). In contrast, as the concentration of $F$. nucleatum increases, the excessive inflammatory effects on trophoblast may negatively affect their function. Indeed, the highest F. nucleatum concentration significantly dampened trophoblast migration, which also brought trophoblast invasion down to control levels.

The analysis of cell survival and the apoptosis rate after $F$. nucleatum treatment suggests that the negative effects on migration observed might be related to the reduced viability or an altered cell cycle after treatment. These negative effects of $F$. nucleatum increased with the concentration and were more evident in the HTR8/SVneo cell line.

After evidencing the effects that might negatively impact on trophoblast function, we focused on the factors that may improve it, especially under treatment with low concentrations of $F$. nucleatum. A factor by which bacteria could promote placentation is by induction of MMPs which facilitate trophoblast invasion. MMPs dysregulation is associated to pregnancy problems (102). Deficient MMP expression may lead to hypertensive disorder and preeclampsia. Excessive MMP release, however, can lead to dysfunctional placentation. In this concern, we observed that $F$. nucleatum could modulate MMP secretion.

We have also explored the capacity of bacteria to affect the release of immune mediators that may affect directly or indirectly functional aspects of trophoblast biology. Trophoblasts release immune mediators that: 1) recruit and modulate the function of several leukocytes populations (decidual NK cells, macrophages, etc) and 2) collaborate with crucial steps of placentation (103,

\section{F. nucleatum}

\section{Invasion \\ Migration}

Viability

Apoptosis

G2/M

$\mathrm{S}$

G0/G1

CXCL-1, IL-8, IL-6

MMP-2, MMP-9

FIGURE 7 | Overview of the schematic effects of rising inactivated $F$. nucleatum concentrations on HTR8/SVneo. Main results of HTR8/SVneo trophoblastic cells in response to in vitro stimulation with F. nucleatum are summarized. F. nucleatum induced HTR8/SVneo invasion, secretion of soluble mediators (CXCL1, IL-6 and IL-8) and metalloproteinases (MMP-2 and MMP-9). As concentrations of $F$. nucleatum increased, these did not improve invasiveness, hindered migration, reduced cell viability and induced alterations in the cell cycle.

104). As the treatment with F. nucleatum affected some of these cytokines, we speculate that these may later influence leukocyte recruitment and function and indirectly trophoblast function. In this scenario, chemokines induced by $F$. nucleatum may act synergistically with the arrival of leukocytes that are known to be important players of placental development, as macrophages and NK cells.

The fact that the cytokine secretion in HTR8/SVneo was induced both in response to F. nucleatum and E. coli treatment led us to a hypothesis that this effect was mediated by LPS. Furthermore, there was no induction of cytokine secretion by BeWo cells, which have a less sensitive TLR4-pathway. Finally, we showed that blocking or inhibition of TLR4 reduced the NF- $\kappa B$ activation and cytokine secretion in F. nucleatum-treated HTR8/ SVneo cells. We postulated that these interactions might be subjected to spatiotemporal conditions in the course of pregnancy, since trophoblast undergoes local and temporal changes in the expression of both TLR4 and E-cadherin. During first trimester, TLR4 is expressed by villous cytotrophoblast (CTB) and extravillous trophoblast cells (EVT), but not by syncytiotrophoblasts $(105,106)$. At term, TLR4 is expressed predominantly by syncytiotrophoblasts $(105,107)$. This pattern is thought to protect the first trimester fetus from deleterious proinflammatory responses caused by bacteria. On the other hand, Ecadherin is expressed in CTB but it is downregulated as EVTs acquire a more invasive phenotype. 
In this scenario, F. nucleatum might interact with EVT secreting MMPs and inducing invasion through the decidual extracellular matrix, pro-inflammatory cytokines (including chemokines) to recruit and interact with decidual leukocytes. The presence of low concentrations of F. nucleatum could support the function of EVT. CTB, on the contrary, are in closer contact to the growing fetus. An excessive proinflammatory environment generated by activation of CTB could threaten fetal health.

The presence of bacteria in the placenta has been reported by histological techniques and later further investigated by molecular-based methods $(29,108,109)$. Furthermore, as these studies are based on the detection of DNA, it cannot be clearly distinguished between bacteria and their products. In our experiments, however, we used inactivated cells. This means that bacterial components that reach target cells may induce similar responses. Furthermore, several gram-negative bacteria including $F$. nucleatum are characterized by the production and release of outer membrane vesicles (OMV). OMV play different roles (including bacterial communication, the modulation of virulence and immune response). As they are small enough to penetrate mucosal barriers, a remote modulatory mechanism of trophoblast function by $F$. nucleatum cannot be ruled out.

Based on our data, we suggest that the presence of lowconcentration of commensal bacteria or bacterial products do not represent a threat to early pregnancy per se. Although the used concentrations only approached in vivo amounts, low bacterial concentrations may mildly stimulate trophoblast cells and support their invasive character. As the upper reproductive tract microbiome may deliver clues to possible, but yet unknown physiological regulation of trophoblast function, we encourage further research to elucidate their constructive role during early pregnancy. Precisely during the review process of this manuscript, a new study showing that Lactobacillus crispatus can promote HTR-8/SVneo invasion supports this idea and reinforces the need for deeper research on this field (110).

\section{REFERENCES}

1. Sender R, Fuchs S, Milo R. Revised Estimates for the Number of Human and Bacteria Cells in the Body. PloS Biol (2016) 14(8):e1002533. doi: 10.1371/ journal.pbio. 1002533

2. Clemente JC, Ursell LK, Parfrey LW, Knight R. The Impact of the Gut Microbiota on Human Health: An Integrative View. Cell (2012) 148 (6):1258-70. doi: 10.1016/j.cell.2012.01.035

3. Martin R, Makino H, Cetinyurek Yavuz A, Ben-Amor K, Roelofs M, Ishikawa E, et al. Early-Life Events, Including Mode of Delivery and Type of Feeding, Siblings and Gender, Shape the Developing Gut Microbiota. PloS One (2016) 11(6):e0158498. doi: 10.1371/journal.pone.0158498

4. Madan JC, Hoen AG, Lundgren SN, Farzan SF, Cottingham KL, Morrison HG, et al. Association of Cesarean Delivery and Formula Supplementation With the Intestinal Microbiome of 6-Week-Old Infants. JAMA Pediatr (2016) 170(3):212-9. doi: 10.1001/jamapediatrics.2015.3732

5. Mbakwa CA, Scheres L, Penders J, Mommers M, Thijs C, Arts IC. Early Life Antibiotic Exposure and Weight Development in Children. J Pediatr (2016) 176:105-13 e2. doi: 10.1016/j.jpeds.2016.06.015

6. Goodrich JK, Waters JL, Poole AC, Sutter JL, Koren O, Blekhman R, et al. Human Genetics Shape the Gut Microbiome. Cell (2014) 159(4):789-99. doi: 10.1016/j.cell.2014.09.053

\section{DATA AVAILABILITY STATEMENT}

The raw data supporting the conclusions of this article will be made available by the authors, without undue reservation.

\section{AUTHOR CONTRIBUTIONS}

$\mathrm{MH}$ and RE performed experiments, analysed data, and contributed to the elaboration of the manuscript. JE performed experiments. MZ contributed with reagents, the design of experiments, and the writing of the manuscript. DM conceived and designed the experiments, analysed data, wrote the paper, and supervised the work. All authors contributed to the article and approved the submitted version.

\section{FUNDING}

This study was supported by intramural funding from Greifswald University. We also acknowledge the support of the Research Network Molecular Medicine (Forschungsverbund Molekulare Medizin, FVMM, FOVB-2021-10).

\section{ACKNOWLEDGMENTS}

We kindly thank Elsa Baufeld from the Friedrich-Loeffler Institute of Medical Microbiology, University of Greifswald, for her support providing the strains of $F$. nucleatum. We also thank Maria Sztachelska for her valuable support with the immunostainings. The authors also acknowledge the Gerhard Domagk programme of the University Medicine Greifswald for its support to $\mathrm{MH}$ and the Landesgraduiertenförderung $\mathrm{MV}$ supporting RE.

7. Shi YC, Guo H, Chen J, Sun G, Ren RR, Guo MZ, et al. Initial Meconium Microbiome in Chinese Neonates Delivered Naturally or by Cesarean Section. Sci Rep (2018) 8(1):3255. doi: 10.1038/s41598-018-21657-7

8. Collado MC, Rautava S, Aakko J, Isolauri E, Salminen S. Human Gut Colonisation May Be Initiated In Utero by Distinct Microbial Communities in the Placenta and Amniotic Fluid. Sci Rep (2016) 6:23129. doi: 10.1038/ srep23129

9. Younge N, McCann JR, Ballard J, Plunkett C, Akhtar S, Araujo-Perez F, et al. Fetal Exposure to the Maternal Microbiota in Humans and Mice. JCI Insight (2019) 4(19):e127806. doi: 10.1172/jci.insight.127806

10. Stinson LF, Boyce MC, Payne MS, Keelan JA. The Not-So-Sterile Womb: Evidence That the Human Fetus Is Exposed to Bacteria Prior to Birth. Front Microbiol (2019) 10:1124. doi: 10.3389/fmicb.2019.01124

11. Walker RW, Clemente JC, Peter I, Loos RJF. The Prenatal Gut Microbiome: Are We Colonized With Bacteria In Utero? Pediatr Obes (2017) 12 Suppl 1:3-17. doi: 10.1111/ijpo.12217

12. Baker JM, Chase DM, Herbst-Kralovetz MM. Uterine Microbiota: Residents, Tourists, or Invaders? Front Immunol (2018) 9:208. doi: 10.3389/ fimmu.2018.00208

13. PrabhuDas M, Bonney E, Caron K, Dey S, Erlebacher A, Fazleabas A, et al. Immune Mechanisms at the Maternal-Fetal Interface: Perspectives and Challenges. Nat Immunol (2015) 16(4):328-34. doi: 10.1038/ni.3131 
14. Fröhlich C, Ehrhardt J, Krüger D, Trojnarska D, Zygmunt M, Muzzio DO. Pregnancy Status Alters IL-21-Mediated Effects on Murine B Lymphocytes. Reproduction (2020) 159(3):351-9. doi: 10.1530/REP-19-0407

15. Einenkel R, Packhäuser KRH, Ehrhardt J, Tüngler A, Zygmunt M, Muzzio DO. CD83 Is Locally Regulated and Differentially Expressed in Disturbed Murine Pregnancy. Reproduction (2019) 158(4):323-33. doi: 10.1530/REP19-0171

16. Muzzio DO, Soldati R, Ehrhardt J, Utpatel K, Evert M, Zenclussen AC, et al. B Cell Development Undergoes Profound Modifications and Adaptations During Pregnancy in Mice. Biol Reprod (2014) 91(5):115. doi: 10.1095/ biolreprod.114.122366

17. Robertson SA, Moldenhauer LM. Immunological Determinants of Implantation Success. Int J Dev Biol (2014) 58(2-4):205-17. doi: 10.1387/ ijdb.140096sr

18. Jensen F, Muzzio D, Soldati R, Fest S, Zenclussen AC. Regulatory B10 Cells Restore Pregnancy Tolerance in a Mouse Model. Biol Reprod (2013) 89 (4):90. doi: 10.1095/biolreprod.113.110791

19. Muzzio D, Zygmunt M, Jensen F. The Role of Pregnancy-Associated Hormones in the Development and Function of Regulatory B Cells. Front Endocrinol (Lausanne) (2014) 5:39. doi: 10.3389/fendo.2014.00039

20. Muzzio DO, Ziegler KB, Ehrhardt J, Zygmunt M, Jensen F. Marginal Zone B Cells Emerge as a Critical Component of Pregnancy Well-Being. Reproduction (2016) 151(1):29-37. doi: 10.1530/REP-15-0274

21. Packhäuser KRH, Roman-Sosa G, Ehrhardt J, Krüger D, Zygmunt M, Muzzio DO. A Kinetic Study of CD83 Reveals an Upregulation and Higher Production of Scd83 in Lymphocytes From Pregnant Mice. Front Immunol (2017) 8:486. doi: 10.3389/fimmu.2017.00486

22. Einenkel R, Ehrhardt J, Hartmann K, Kruger D, Muzzio DO, Zygmunt M. Hormonally Controlled ILC Antigen Presentation Potential Is Reduced During Pregnancy. Reproduction (2020) 160(1):155-69. doi: 10.1530/REP19-0554

23. Zygmunt M, Herr F, Münstedt K, Lang U, Liang OD. Angiogenesis and Vasculogenesis in Pregnancy. Eur J Obstet Gynecol Reprod Biol (2003) 110 Suppl 1:S10-8. doi: 10.1016/s0301-2115(03)00168-4

24. Lima PD, Zhang J, Dunk C, Lye SJ, Croy BA. Leukocyte Driven-Decidual Angiogenesis in Early Pregnancy. Cell Mol Immunol (2014) 11(6):522-37. doi: $10.1038 / \mathrm{cmi} .2014 .63$

25. Erlebacher A. Immunology of the Maternal-Fetal Interface. Annu Rev Immunol (2013) 31:387-411. doi: 10.1146/annurev-immunol-032712100003

26. Mor G, Cardenas I. The Immune System in Pregnancy: A Unique Complexity. Am J Reprod Immunol (2010) 63(6):425-33. doi: 10.1111/ j.1600-0897.2010.00836.x

27. Cicinelli E, De Ziegler D, Nicoletti R, Tinelli R, Saliani N, Resta L, et al. Poor Reliability of Vaginal and Endocervical Cultures for Evaluating Microbiology of Endometrial Cavity in Women With Chronic Endometritis. Gynecol Obstet Invest (2009) 68(2):108-15. doi: 10.1159/ 000223819

28. Aagaard K, Ma J, Antony KM, Ganu R, Petrosino J, Versalovic J. The Placenta Harbors a Unique Microbiome. Sci Transl Med (2014) 6 (237):237ra65. doi: 10.1126/scitranslmed.3008599

29. Stout MJ, Conlon B, Landeau M, Lee I, Bower C, Zhao Q, et al. Identification of Intracellular Bacteria in the Basal Plate of the Human Placenta in Term and Preterm Gestations. Am J Obstet Gynecol (2013) 208(3):226 e1-7. doi: 10.1016/j.ajog.2013.01.018

30. Parnell LA, Briggs CM, Cao B, Delannoy-Bruno O, Schrieffer AE, Mysorekar IU. Microbial Communities in Placentas From Term Normal Pregnancy Exhibit Spatially Variable Profiles. Sci Rep (2017) 7(1):11200. doi: 10.1038/ s41598-017-11514-4

31. Jimenez E, Fernandez L, Marin ML, Martin R, Odriozola JM, Nueno-Palop C, et al. Isolation of Commensal Bacteria From Umbilical Cord Blood of Healthy Neonates Born by Cesarean Section. Curr Microbiol (2005) 51 (4):270-4. doi: 10.1007/s00284-005-0020-3

32. Lauder AP, Roche AM, Sherrill-Mix S, Bailey A, Laughlin AL, Bittinger K, et al. Comparison of Placenta Samples With Contamination Controls Does Not Provide Evidence for a Distinct Placenta Microbiota. Microbiome (2016) 4(1):29. doi: 10.1186/s40168-016-0172-3
33. de Goffau MC, Lager S, Sovio U, Gaccioli F, Cook E, Peacock SJ, et al. Human Placenta Has No Microbiome But Can Contain Potential Pathogens. Nature (2019) 572(7769):329-34. doi: 10.1038/s41586-019-1451-5

34. Kuperman AA, Zimmerman A, Hamadia S, Ziv O, Gurevich V, Fichtman B, et al. Deep Microbial Analysis of Multiple Placentas Shows No Evidence for a Placental Microbiome. BJOG (2020) 127(2):159-69. doi: 10.1111/14710528.15896

35. Theis KR, Romero R, Winters AD, Greenberg JM, Gomez-Lopez N, Alhousseini A, et al. Does the Human Placenta Delivered at Term Have a Microbiota? Results of Cultivation, Quantitative Real-Time PCR, 16s rRNA Gene Sequencing, and Metagenomics. Am J Obstet Gynecol (2019) 220 (3):267.e1-39. doi: 10.1016/j.ajog.2018.10.018

36. Mor G, Kwon JY. Trophoblast-Microbiome Interaction: A New Paradigm on Immune Regulation. Am J Obstet Gynecol (2015) 213(4 Suppl):S131-7. doi: 10.1016/j.ajog.2015.06.039

37. Einenkel R, Zygmunt M, Muzzio DO. Microorganisms in the Healthy Upper Reproductive Tract: From Denial to Beneficial Assignments for Reproductive Biology. Reprod Biol (2019) 19(2):113-8. doi: 10.1016/ j.repbio.2019.04.001

38. Bolstad AI, Jensen HB, Bakken V. Taxonomy, Biology, and Periodontal Aspects of Fusobacterium Nucleatum. Clin Microbiol Rev (1996) 9(1):55-71. doi: 10.1128/CMR.9.1.55

39. Kostic AD, Chun E, Robertson L, Glickman JN, Gallini CA, Michaud M, et al. Fusobacterium Nucleatum Potentiates Intestinal Tumorigenesis and Modulates the Tumor-Immune Microenvironment. Cell Host Microbe (2013) 14(2):207-15. doi: 10.1016/j.chom.2013.07.007

40. Castellarin M, Warren RL, Freeman JD, Dreolini L, Krzywinski M, Strauss J, et al. Fusobacterium Nucleatum Infection Is Prevalent in Human Colorectal Carcinoma. Genome Res (2012) 22(2):299-306. doi: 10.1101/gr.126516.111

41. Gendron R, Plamondon P, Grenier D. Binding of Pro-Matrix Metalloproteinase 9 by Fusobacterium Nucleatum Subsp. Nucleatum as a Mechanism to Promote the Invasion of a Reconstituted Basement Membrane. Infect Immun (2004) 72(10):6160-3. doi: 10.1128/ IAI.72.10.6160-6163.2004

42. Uitto VJ, Baillie D, Wu Q, Gendron R, Grenier D, Putnins EE, et al. Fusobacterium Nucleatum Increases Collagenase 3 Production and Migration of Epithelial Cells. Infect Immun (2005) 73(2):1171-9. doi: 10.1128/IAI.73.2.1171-1179.2005

43. Gursoy UK, Kononen E, Uitto VJ. Stimulation of Epithelial Cell Matrix Metalloproteinase (MMP-2, -9, -13) and Interleukin-8 Secretion by Fusobacteria. Oral Microbiol Immunol (2008) 23(5):432-4. doi: 10.1111/ j.1399-302X.2008.00453.x

44. Rubinstein MR, Wang X, Liu W, Hao Y, Cai G, Han YW. Fusobacterium Nucleatum Promotes Colorectal Carcinogenesis by Modulating E-Cadherin/ Beta-Catenin Signaling via its FadA Adhesin. Cell Host Microbe (2013) 14 (2):195-206. doi: 10.1016/j.chom.2013.07.012

45. Gur C, Ibrahim Y, Isaacson B, Yamin R, Abed J, Gamliel M, et al. Binding of the Fap2 Protein of Fusobacterium Nucleatum to Human Inhibitory Receptor TIGIT Protects Tumors From Immune Cell Attack. Immunity (2015) 42(2):344-55. doi: 10.1016/j.immuni.2015.01.010

46. Abed J, Emgard JE, Zamir G, Faroja M, Almogy G, Grenov A, et al. Fap2 Mediates Fusobacterium Nucleatum Colorectal Adenocarcinoma Enrichment by Binding to Tumor-Expressed Gal-GalNAc. Cell Host Microbe (2016) 20(2):215-25. doi: 10.1016/j.chom.2016.07.006

47. Bashir A, Miskeen AY, Bhat A, Fazili KM, Ganai BA. Fusobacterium Nucleatum: An Emerging Bug in Colorectal Tumorigenesis. Eur J Cancer Prev (2015) 24(5):373-85. doi: 10.1097/CEJ.0000000000000116

48. Nosho K, Sukawa Y, Adachi Y, Ito M, Mitsuhashi K, Kurihara H, et al. Association of Fusobacterium Nucleatum With Immunity and Molecular Alterations in Colorectal Cancer. World J Gastroenterol (2016) 22(2):557-66. doi: 10.3748/wjg.v22.i2.557

49. Shenker BJ, DiRienzo JM. Suppression of Human Peripheral Blood Lymphocytes by Fusobacterium Nucleatum. J Immunol (1984) 132 (5):2357-62.

50. Shenker BJ, Datar S. Fusobacterium Nucleatum Inhibits Human T-Cell Activation by Arresting Cells in the Mid-G1 Phase of the Cell Cycle. Infect Immun (1995) 63(12):4830-6. doi: 10.1128/iai.63.12.4830-4836.1995 
51. Demuth DR, Savary R, Golub E, Shenker BJ. Identification and Analysis of Fipa, a Fusobacterium Nucleatum Immunosuppressive Factor Gene. Infect Immun (1996) 64(4):1335-41. doi: 10.1128/iai.64.4.1335-1341.1996

52. Mangan DF, Won T, Lopatin DE. Monocyte Suppression of Fusobacterium Nucleatum-Induced Human Polyclonal B-Lymphocyte Activation. Infect Immun (1984) 46(2):332-9. doi: 10.1128/iai.46.2.332-339.1984

53. Grenier D, Grignon L. Response of Human Macrophage-Like Cells to Stimulation by Fusobacterium Nucleatum Ssp. Nucleatum Lipopolysaccharide. Oral Microbiol Immunol (2006) 21(3):190-6. doi: 10.1111/j.1399-302X.2006.00278.x

54. Ghosh SK, Gupta S, Jiang B, Weinberg A. Fusobacterium Nucleatum and Human Beta-Defensins Modulate the Release of Antimicrobial Chemokine CCL20/Macrophage Inflammatory Protein 3alpha. Infect Immun (2011) 79 (11):4578-87. doi: 10.1128/IAI.05586-11

55. Birchmeier W, Hulsken J, Behrens J. E-Cadherin as an Invasion Suppressor. Ciba Found Symp (1995) 189:124-36. doi: 10.1002/9780470514719.ch10

56. Wong SHM, Fang CM, Chuah LH, Leong CO, Ngai SC. E-Cadherin: Its Dysregulation in Carcinogenesis and Clinical Implications. Crit Rev Oncol Hematol (2018) 121:11-22. doi: 10.1016/j.critrevonc.2017.11.010

57. Holtan SG, Creedon DJ, Haluska P, Markovic SN. Cancer and Pregnancy: Parallels in Growth, Invasion, and Immune Modulation and Implications for Cancer Therapeutic Agents. Mayo Clin Proc (2009) 84(11):985-1000. doi: 10.1016/S0025-6196(11)60669-1

58. Mahtout H, Chandad F, Rojo JM, Grenier D. Fusobacterium Nucleatum Binding to Complement Regulatory Protein CD46 Modulates the Expression and Secretion of Cytokines and Matrix Metalloproteinases by Oral Epithelial Cells. J Periodontol (2011) 82(2):311-9. doi: 10.1902/jop.2010.100458

59. Floridon C, Nielsen O, Holund B, Sunde L, Westergaard JG, Thomsen SG, et al. Localization of E-Cadherin in Villous, Extravillous and Vascular Trophoblasts During Intrauterine, Ectopic and Molar Pregnancy. Mol Hum Reprod (2000) 6(10):943-50. doi: 10.1093/molehr/6.10.943

60. Kokkinos MI, Murthi P, Wafai R, Thompson EW, Newgreen DF. Cadherins in the Human Placenta-Epithelial-Mesenchymal Transition (EMT) and Placental Development. Placenta (2010) 31(9):747-55. doi: 10.1016/ j.placenta.2010.06.017

61. Pollheimer J, Loregger T, Sonderegger S, Saleh L, Bauer S, Bilban M, et al. Activation of the Canonical Wingless/T-Cell Factor Signaling Pathway Promotes Invasive Differentiation of Human Trophoblast. Am J Pathol (2006) 168(4):1134-47. doi: 10.2353/ajpath.2006.050686

62. Petrova YI, Schecterson L, Gumbiner BM. Roles for E-Cadherin Cell Surface Regulation in Cancer. Mol Biol Cell (2016) 27(21):3233-44. doi: 10.1091/ mbc.E16-01-0058

63. Romero R, Dey SK, Fisher SJ. Preterm Labor: One Syndrome, Many Causes. Science (2014) 345(6198):760-5. doi: 10.1126/science.1251816

64. Garcia-So J, Zhang X, Yang X, Rubinstein MR, Mao Y, Kitajewski J, et al. Omega-3 Fatty Acids Suppress Fusobacterium Nucleatum-Induced Placental Inflammation Originating From Maternal Endothelial Cells. JCI Insight (2019) 4(3):e125436. doi: 10.1172/jci.insight.125436

65. Bowes WA. The Role of Antibiotics in the Prevention of Preterm Birth. F1000 Med Rep (2009) 1:22. doi: 10.3410/M1-22

66. Pelzer ES, Willner D, Buttini M, Hafner LM, Theodoropoulos C, Huygens F. The Fallopian Tube Microbiome: Implications for Reproductive Health. Oncotarget (2018) 9(30):21541-51. doi: 10.18632/oncotarget.25059

67. Zhou B, Sun C, Huang J, Xia M, Guo E, Li N, et al. The Biodiversity Composition of Microbiome in Ovarian Carcinoma Patients. Sci Rep (2019) 9(1):1691. doi: 10.1038/s41598-018-38031-2

68. Yu B, Liu C, Fredricks D, Swisher E. Microbiome Profiling of Fallopian Tubes. Gynecol Oncol (2020) 156(3):e26. doi: 10.1016/j.ygyno.2019.11.085

69. Brundin M, Figdor D, Sundqvist G, Sjogren U. Preservation of Fusobacterium Nucleatum and Peptostreptococcus Anaerobius DNA After Loss of Cell Viability. Int Endod J (2015) 48(1):37-45. doi: 10.1111/ iej. 12273

70. Tang B, Wang K, Jia YP, Zhu P, Fang Y, Zhang ZJ, et al. Fusobacterium Nucleatum-Induced Impairment of Autophagic Flux Enhances the Expression of Proinflammatory Cytokines via ROS in Caco-2 Cells. PloS One (2016) 11(11):e0165701. doi: 10.1371/journal.pone.0165701

71. Sayed IM, Chakraborty A, Abd El-Hafeez AA, Sharma A, Sahan AZ, Huang WJM, et al. The DNA Glycosylase NEIL2 Suppresses
Fusobacterium-Infection-Induced Inflammation and DNA Damage in Colonic Epithelial Cells. Cells (2020) 9(9):1980. doi: 10.3390/ cells 9091980

72. Kang W, Ji X, Zhang X, Tang D, Feng Q. Persistent Exposure to Fusobacterium Nucleatum Triggers Chemokine/Cytokine Release and Inhibits the Proliferation and Osteogenic Differentiation Capabilities of Human Gingiva-Derived Mesenchymal Stem Cells. Front Cell Infect Microbiol (2019) 9:429. doi: 10.3389/fcimb.2019.00429

73. Tuttle RS, Mangan DF. Interaction of Fusobacterium Nucleatum 191 With Human Peripheral Blood Lymphocytes. J Periodontal Res (1990) 25(6):36471. doi: 10.1111/j.1600-0765.1990.tb00929.x

74. Riccardi C, Nicoletti I. Analysis of Apoptosis by Propidium Iodide Staining and Flow Cytometry. Nat Protoc (2006) 1(3):1458-61. doi: 10.1038/ nprot.2006.238

75. Watson JV, Chambers SH, Smith PJ. A Pragmatic Approach to the Analysis of DNA Histograms With a Definable G1 Peak. Cytometry (1987) 8(1):1-8. doi: 10.1002/cyto.990080101

76. Mor G, Abrahams VM. Potential Role of Macrophages as Immunoregulators of Pregnancy. Reprod Biol Endocrinol (2003) 1:119. doi: 10.1186/1477-7827$1-119$

77. Koh YQ, Chan HW, Nitert MD, Vaswani K, Mitchell MD, Rice GE. Differential Response to Lipopolysaccharide by JEG-3 and BeWo Human Choriocarcinoma Cell Lines. Eur J Obstet Gynecol Reprod Biol (2014) 175:129-33. doi: 10.1016/j.ejogrb.2013.12.032

78. Cardenas I, Mor G, Aldo P, Lang SM, Stabach P, Sharp A, et al. Placental Viral Infection Sensitizes to Endotoxin-Induced Pre-Term Labor: A Double Hit Hypothesis. Am J Reprod Immunol (2011) 65(2):110-7. doi: 10.1111/ j.1600-0897.2010.00908.x

79. Hongqi L, Raymond WR, Yiping WH. Fusobacterium Nucleatum Induces Fetal Death in Mice via Stimulation of TLR4-Mediated Placental Inflammatory Response. J Immunol (2007) 179(4):2501-8. doi: 10.4049/ jimmunol.179.4.2501

80. Kong C, Yan X, Zhu Y, Zhu H, Luo Y, Liu P, et al. Fusobacterium Nucleatum Promotes the Development of Colorectal Cancer by Activating a Cytochrome P450/epoxyoctadecenoic Acid Axis via TLR4/Keap1/NRF2 Signaling. Cancer Res (2021). doi: 10.1158/0008-5472.can-21-0453

81. Lijun H, Yan L, Xuehua K, Rui W, Qi P, Yan Z, et al. Fusobacterium Nucleatum Facilitates M2 Macrophage Polarization and Colorectal

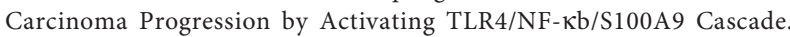
Front Immunol (2021) 12:658681. doi: 10.3389/fimmu.2021.658681

82. Ting C, Qing L, Jiao W, Yaxin W, Wei P, Wei P, et al. Fusobacterium Nucleatum Promotes M2 Polarization of Macrophages in the Microenvironment of Colorectal Tumours via a TLR4-Dependent Mechanism. Cancer Immunol Immunother (2018) 67:1635-6. doi: 10.1007/ s00262-018-2233-x

83. Yaxin W, Jiao W, Ting C, Qing L, Wei P, Huan L, et al. Fusobacterium Nucleatum Potentiates Intestinal Tumorigenesis in Mice via a Toll-Like Receptor 4/P21-Activated Kinase 1 Cascade. Digest Dis Sci (2018) 63:1210-8. doi: 10.1007/s10620-018-4999-2

84. Kinder Haake S, Lindemann RA. Fusobacterium Nucleatum T18 Aggregates Human Mononuclear Cells and Inhibits Their PHA-Stimulated Proliferation. J Periodontol (1997) 68(1):39-44. doi: 10.1902/jop.1997.68.1.39

85. Ma CT, Luo HS, Gao F, Tang QC, Chen W. Fusobacterium Nucleatum Promotes the Progression of Colorectal Cancer by Interacting With ECadherin. Oncol Lett (2018) 16(2):2606-12. doi: 10.3892/ol.2018.8947

86. Rubinstein MR, Baik JE, Lagana SM, Han RP, Raab WJ, Sahoo D, et al. Fusobacterium Nucleatum Promotes Colorectal Cancer by Inducing Wnt/ Beta-Catenin Modulator Annexin A1. EMBO Rep (2019) 20(4):e47638. doi: $10.15252 /$ embr. 201847638

87. Stockham S, Stamford JE, Roberts CT, Fitzsimmons TR, Marchant C, Bartold PM, et al. Abnormal Pregnancy Outcomes in Mice Using an Induced Periodontitis Model and the Haematogenous Migration of Fusobacterium Nucleatum Sub-Species to the Murine Placenta. PloS One (2015) 10(3):e0120050. doi: 10.1371/journal.pone.0120050

88. Han YW, Redline RW, Li M, Yin L, Hill GB, McCormick TS. Fusobacterium Nucleatum Induces Premature and Term Stillbirths in Pregnant Mice: Implication of Oral Bacteria in Preterm Birth. Infect Immun (2004) 72 (4):2272-9. doi: 10.1128/iai.72.4.2272-2279.2004 
89. Han YW, Fardini Y, Chen C, Iacampo KG, Peraino VA, Shamonki JM, et al. Term Stillbirth Caused by Oral Fusobacterium Nucleatum. Obstet Gynecol (2010) 115(2 Pt 2):442-5. doi: 10.1097/AOG.0b013e3181cb9955

90. Ikegami A, Chung P, Han YW. Complementation of the fadA Mutation in Fusobacterium Nucleatum Demonstrates That the Surface-Exposed Adhesin Promotes Cellular Invasion and Placental Colonization. Infect Immun (2009) 77(7):3075-9. doi: 10.1128/IAI.00209-09

91. Gauthier S, Tetu A, Himaya E, Morand M, Chandad F, Rallu F, et al. The Origin of Fusobacterium Nucleatum Involved in Intra-Amniotic Infection and Preterm Birth. J Matern Fetal Neonatal Med (2011) 24(11):1329-32. doi: 10.3109/14767058.2010.550977

92. Vander Haar EL, So J, Gyamfi-Bannerman C, Han YW. Fusobacterium Nucleatum and Adverse Pregnancy Outcomes: Epidemiological and Mechanistic Evidence. Anaerobe (2018) 50:55-9. doi: 10.1016/j. anaerobe.2018.01.008

93. Chan E, Brundler MA, Zhang K. Identification of Fusobacterium Nucleatum in Formalin-Fixed, Paraffin-Embedded Placental Tissues by 16S rRNA Sequencing in a Case of Extremely Preterm Birth Secondary to Amniotic Fluid Infection. Pathology (2019) 51(3):320-2. doi: 10.1016/j.pathol.2018.11.013

94. Hounkonnou CPA, Briand V, Fievet N, Accrombessi M, Yovo E, Mama A, et al. Dynamics of Submicroscopic Plasmodium Falciparum Infections Throughout Pregnancy: A Preconception Cohort Study in Benin. Clin Infect Dis (2020) 71(1):166-74. doi: 10.1093/cid/ciz748

95. Tuikue Ndam N, Tornyigah B, Dossou AY, Escriou G, Nielsen MA, Salanti A, et al. Persistent Plasmodium Falciparum Infection in Women With an Intent to Become Pregnant as a Risk Factor for Pregnancy-Associated Malaria. Clin Infect Dis (2018) 67(12):1890-6. doi: 10.1093/cid/ciy380

96. Aldo P, You Y, Szigeti K, Horvath TL, Lindenbach B, Mor G. HSV-2 Enhances ZIKV Infection of the Placenta and Induces Apoptosis in FirstTrimester Trophoblast Cells. Am J Reprod Immunol (2016) 76(5):348-57. doi: 10.1111/aji.12578

97. Garcia AG, Marques RL, Lobato YY, Fonseca ME, Wigg MD. Placental Pathology in Congenital Rubella. Placenta (1985) 6(4):281-95. doi: 10.1016/ s0143-4004(85)80038-2

98. Chua CLL, Hasang W, Rogerson SJ, Teo A. Poor Birth Outcomes in Malaria in Pregnancy: Recent Insights Into Mechanisms and Prevention Approaches. Front Immunol (2021) 12:621382. doi: 10.3389/fimmu.2021.621382

99. Fest S, Aldo PB, Abrahams VM, Visintin I, Alvero A, Chen R, et al. Trophoblast-Macrophage Interactions: A Regulatory Network for the Protection of Pregnancy. Am J Reprod Immunol (2007) 57(1):55-66. doi: 10.1111/j.1600-0897.2006.00446.x

100. Moraes JGN, Silva PRB, Mendonca LGD, Scanavez AA, Silva JCC, Chebel RC. Effects of Intrauterine Infusion of Escherichia Coli Lipopolysaccharide on Uterine Health, Resolution of Purulent Vaginal Discharge, and Reproductive Performance of Lactating Dairy Cows. J Dairy Sci (2017) 100 (6):4772-83. doi: 10.3168/jds.2016-11630

101. Moraes JGN, Mendonca LGD, Silva PRB, Scanavez AA, Galvao KN, Ballou $\mathrm{MA}$, et al. Effects of Intrauterine Infusion of Escherichia Coli Lipopolysaccharide on Uterine mRNA Gene Expression and Peripheral Polymorphonuclear Leukocytes in Jersey Cows Diagnosed With Purulent Vaginal Discharge. J Dairy Sci (2017) 100(6):4784-96. doi: 10.3168/ jds.2016-11643
102. Nikolov A, Popovski N. Role of Gelatinases MMP-2 and MMP-9 in Healthy and Complicated Pregnancy and Their Future Potential as Preeclampsia Biomarkers. Diag (Basel) (2021) 11(3):480. doi: 10.3390/diagnostics 11030480

103. Wallace AE, Fraser R, Cartwright JE. Extravillous Trophoblast and Decidual Natural Killer Cells: A Remodelling Partnership. Hum Reprod Update (2012) 18(4):458-71. doi: 10.1093/humupd/dms015

104. Grasso E, Paparini D, Hauk V, Salamone G, Leiros CP, Ramhorst R. Differential Migration and Activation Profile of Monocytes After Trophoblast Interaction. PloS One (2014) 9(5):e97147. doi: 10.1371/ journal.pone.0097147

105. Beijar EC, Mallard C, Powell TL. Expression and Subcellular Localization of TLR-4 in Term and First Trimester Human Placenta. Placenta (2006) 27(23):322-6. doi: 10.1016/j.placenta.2004.12.012

106. Holmlund U, Cebers G, Dahlfors AR, Sandstedt B, Bremme K, Ekstrom ES, et al. Expression and Regulation of the Pattern Recognition Receptors Toll-Like Receptor-2 and Toll-Like Receptor-4 in the Human Placenta. Immunology (2002) 107(1):145-51. doi: 10.1046/j.1365-2567.2002. 01491.x

107. Abrahams VM, Bole-Aldo P, Kim YM, Straszewski-Chavez SL, Chaiworapongsa T, Romero R, et al. Divergent Trophoblast Responses to Bacterial Products Mediated by TLRs. J Immunol (2004) 173(7):4286-96 doi: 10.4049/jimmunol.173.7.4286

108. Cao B, Mysorekar IU. Intracellular Bacteria in Placental Basal Plate Localize to Extravillous Trophoblasts. Placenta (2014) 35(2):139-42. doi: 10.1016/ j.placenta.2013.12.007

109. Seferovic MD, Pace RM, Carroll M, Belfort B, Major AM, Chu DM, et al. Visualization of Microbes by $16 \mathrm{~S}$ In Situ Hybridization in Term and Preterm Placentas Without Intraamniotic Infection. Am J Obstet Gynecol (2019) 221 (2):146 e1- e23. doi: 10.1016/j.ajog.2019.04.036

110. Yoshida T, Takada K, Komine-Aizawa S, Kamei Y, Ishihara O, Hayakawa S. Lactobacillus Crispatus Promotes Invasion of the HTR-8/SVneo Trophoblast Cell Line. Placenta (2021) 111:76-81. doi: 10.1016/ j.placenta.2021.06.006

Conflict of Interest: The authors declare that the research was conducted in the absence of any commercial or financial relationships that could be construed as a potential conflict of interest.

Publisher's Note: All claims expressed in this article are solely those of the authors and do not necessarily represent those of their affiliated organizations, or those of the publisher, the editors and the reviewers. Any product that may be evaluated in this article, or claim that may be made by its manufacturer, is not guaranteed or endorsed by the publisher.

Copyright (C) 2021 Heusler, Einenkel, Ehrhardt, Muzzio and Zygmunt. This is an open-access article distributed under the terms of the Creative Commons Attribution License (CC BY). The use, distribution or reproduction in other forums is permitted, provided the original author(s) and the copyright owner(s) are credited and that the original publication in this journal is cited, in accordance with accepted academic practice. No use, distribution or reproduction is permitted which does not comply with these terms. 